\title{
Stability of Symmetrical Motions Driven by Latent Heat Release by Cumulus Convection under the Existence of Surface Friction*
}

\author{
By S. Syōno and M. Yamasaki \\ Geophysical Institute, Tokyo University, Tokyo \\ (Manuscript received 17 August 1966)
}

\begin{abstract}
To obtain a theoretical basis for the numerical simulation of tropical cyclones, the stability properties of symmetrical disturbances driven by the latent heat of condensation released in deep cumulus clouds under the existence of surface friction are discussed by solving a system of primitive thermohydrodynamic equations applied to a three-layer model including the friction layer. The processes of heat generation and transfer by cumulus clouds are incorporated by assuming that the total amount of latent heat released in any vertical column of air is proportional to the horizontal convergence in the friction layer.

An analysis of linear perturbation equations shows that a typhoon-scale disturbance similar to those obtained by Ooyama (1963), Charney and Eliassen (1964) and Ogura (1964) using the balanced model is also found in the unbalanced (or primitive) model. Without surface friction the disturbance would be in geostrophic (or gradient wind) balance. Under some conditions unstable gravity waves as discussed by Haque (1952) and Syōno (1953) still exist even in our model in spite of a different treatment of condensational heating. Moreover, under some conditions gravity oscillations are amplified with a large amplification rate and short period. These unstable gravity waves are found to be filtered out by use of the assumption that the pressure gradient force is balanced with the Coriolis force and the frictional force in the friction layer, as adopted by Ooyama (1963) and others. At the same time the use of this assumption modifies the growth rate of the typhoon-scale disturbance. Furthermore this assumption alters the condition under which the typhoon-scale disturbance exists. The analysis further shows that the vertical partition of the released latent heat as well as the amount of water vapor in the ascending air and the static stability of the atmosphere are important factors which determine properties of the disturbance.
\end{abstract}

\section{Introduction}

The major objectives of this study are to find out some of the physical constraints under which typhoon-scale disturbances develop, and to obtain a theoretical basis for the numerical simulation of the development of tropical cyclones.

The primary source of energy for the development and the maintenance of tropical cyclones is undoubtedly the released latent heat of condensation of water vapor. However, the mechanism in which the released latent heat contributes to the development has not been explained completely.

When Haque (1952) and Syōno (1953) first

* Division of Meteorology, Contribution No. 150. attempted to discuss the development of tropical cyclones theoretically, they attributed the development directly to conditionally unstable stratification of the atmosphere. Along the line of this theory some numerical experiments to simulate the typhoon-development were carried out decade later by Kasahara (1961) and Syōno (1962). In their experiments small scale disturbances whose horizontal scale was less than one hundred kilometers developed very rapidly, and the simulation of the typhoon-development was not successful. Their results showed that the motions which grow rapidly in the conditionally unstable atmosphere are small-scale disturbances such as cumulus clouds. Inability of the gravitational instability theory to explain the growth of large-scale tropical cyclones was also shown 
from linear perturbation analyses by Lilly (1960), Kuo (1961) and Yanai (1961b).

Nevertheless, cumulonimbus convection must play an important role in the development and the maintenance of tropical cyclones. Riehl and Malkus (1961) pointed out the role played by "hot tower" comulonimbus clouds in the thermal budget of a growing hurricane. Yanai (1961a) inferred the importance of the upward transport of heat by penetrative cloud towers for the warm core formation at the formative stage of a typhoon. Riehl and Malkus (1961) and Yanai (1961b) further suggested to parameterize the effect of cumclus-scale heat transfer in the framework of a dynamical model of a large-scale tropical cyclone. These results have led several workers in this field to search for a better formulation of the problem, that is, to develop a theory for the tropical cyclone in which the effect of small-scale cumulonimbus clouds is properly incorporated. Several earlier attempts have been reviewed by Yanai (1964).

The first successful "parametrization" of cumulus convection into the tropical cyclone model was that of Ooyama (1963). He assumed that the rate of total heat production by convective clouds in a vertical column is proportional to the supply of water vapor in the column by the large scale horizontal convergence in the surface boundary layer. Thus he related the heating by cumulus convection to the dynamics of the large scale circulation through surface friction. By a perturbation analysis he was able to describe a disturbance similar to a tropical cyclone with respect to the growth rate and the preferred scale. Charney and Eliassen (1964) and Ogura (1964) discussed the growth of the tropical cyclone in a similar way.

Ogura (1964) further carried out a numerical calculation to simulate the development of a tropical cyclone. He succeeded in obtaining the development of a typhoon-scale disturbance, but his results allowed unlimited growth of the disturbance. Kuo (1965) also carried out numerical calculations for two models in which the effect of surface friction was incorporated in different manner. In a model without a separate friction layer he succeeded in simulating the development and the quasisteady state of a tropical cyclone. On the other hand in a model in which the effect of friction in the boundary layer is incorporated as a condition on the vertical velocity at the top of the friction layer, as adopted by Ooyama (1963) and others, he did not obtain a quasisteady state. Ogura (1964) and Kuo (1965) pointed out the importance of the appropriate formulation of the friction layer in order to simulate the development of a tropical cyclone successfully. It should be mentioned that all of these studies used the balanced model in which a balance between the wind and the pressure was assumed.

At Tokyo University, we have continued the study of tropical cyclone development by numerical integrations of the primitive equations. In early experiments (Syōno and Hirota, $1963)^{*}$ the development of a tropical cyclone was not well simulated because the coupling between cumulus convection and large scale circulation was weak. Later on, we have used an improved model in which the heating process was parameterized as proposed by Ooyama. Furthermore we have applied primitive equations of motion to the surface layer as well as to the free atmosphere. In this model we have experienced a difficulty of having shortperiod amplifying oscillations. By using a device that the total amount of latent heat released in a vertical column of air is assumed to be proportional to some weighted spaceaverage of horizontal convergence in the lowest layer, such a difficulty was removed and a quasi-steady state of a well-developed disturbance similar to a tropical cyclone was obtained (Syōno and Matsuno, 1963).** The experience of having amplifying oscillations has led us to examine the stability properties of disturbances for the unbalanced (or primitive) model.

In this paper we shall investigate the following points.

(1) Ooyama (1963) and others discussed the growth of the tropical cyclone with the assumption of balance between the pressure and the wind. They did not clarify whether it is necessary to assume the geostrophic (or gradient wind) balance in order to obtain a typhoon-

* Paper presented at the International Symposium of Large-Scale Processes, Boulder, 1963.

** Unpublished work. 
scale disturbance. One of our concerns is to investigate whether such a disturbance is found in a model without the assumption of balance.

(2) They attributed the horizontal convergence that occurred in the surface boundary layer directly to the effect of surface friction. They assumed that the pressure gradient force are balanced with the Coriolis force and the frictional force in the surface layer. Therefore, the horizontal convergence in the surface layer is caused only by the surface friction, and the possibility of the allobaric (or isallobaic) effect as a cause of convergence is completely excluded in their models. In this study by including this possibility we shall deal with the problem more in general. It will be later shown that the assumption adopted by Ooyama (1963) and others filters out two types of waves and also modifies some properties of the typhoon-scale disturbance.

(3) Our third concern is to learn why and under what conditions short-period gravity oscillations are amplified, when the effect of latent heat released by cumulus convection is included in the same manner that Ooyama (1963) proposed. Such amplifying oscillations tended to obscure the large-scale motion in the numerical simulation of a tropical cyclone carried out by Syōno and Matsuno.

(4) The relation between some properties of disturbances and the vertical distribution of heat sources will be discussed in this paper. Ooyama (1963) and others discussed the properties of disturbances in a two-layer model in which the temperature is defined at only one level, while in our model the temperature change is considered at two levels. As will be shown later, such a model has an advantage for the interpretation of amplifying gravity oscillations mentioned above. Moreover it will be shown that the vertical distribution of the released heat is an important factor in determining the growth and the structure of the typhoon-scale disturbance.

\section{Model and basic assumptions}

\section{1. basic equations}

Our problem is to investigate the properties of macro-scale motions driven by latent heat released by cumulus convection when surface friction is considered. For the sake of simplicity we shall deal with slab-symmetrical dis- turbances whose properties do not depend upon the $y$-direction in the Cartesian coordinate system $(x, y, p)$. Basic equations are written as follows:

$$
\begin{aligned}
& \frac{d u}{d t}-f v=-\frac{\partial \phi}{\partial x}+\nu \frac{\partial^{2} u}{\partial x^{2}}-g \frac{\partial \tau_{x}}{\partial p} \\
& \frac{d v}{d t}+f u=\nu \frac{\partial^{2} v}{\partial x^{2}}-g \frac{\partial \tau_{y}}{\partial p} \\
& \frac{\partial \phi}{\partial p}=-\frac{R}{p}\left(\frac{p}{p_{0}}\right)^{R / c_{p}} \theta \\
& \frac{\partial u}{\partial x}+\frac{\partial \omega}{\partial p}=0 \\
& \frac{d \theta}{d t}=\frac{\theta}{c_{p} T} Q+\kappa \frac{\partial^{2} \theta}{\partial x^{2}}
\end{aligned}
$$

where

$$
\frac{d}{d t} \equiv \frac{\partial}{\partial t}+u \frac{\partial}{\partial x}+\omega \frac{\partial}{\partial p} .
$$

Symbols are:

$u=$ component of horizontal wind velocity in the $x$-direction

$v=$ component of horizontal wind velocity

in the $y$-direction

$\omega=$ vertical $p$-velocity

$\phi=$ geopotential

$\theta=$ potential temperature

$T=$ temperature

$f=$ Coriolis parameter

$g=$ accerelation of gravity

$c_{p}=$ specific heat of air at constant pressure

$R=$ gas constant of air

$p_{0}=$ reference pressure taken as $1,000 \mathrm{mb}$

$\nu=$ horizontal eddy viscosity coefficient

$\kappa=$ horizontal eddy thermal diffusivity coefficient

$\tau_{x}=$ component of vertical stress in the $x$ direction

$\tau_{y}=$ component of vertical stress in the $y$ direction

$Q=$ rate of non-adiabatic heating per unit mass

The first two equations are the equations of motion in the $x$ and $y$ direction, respectively. The third equation represents the hydrostatic relation. Since we are interested in the motions whose horizontal dimension is much larger than the vertical one, the use of this approximation will be permitted. The fourth equation is the conservation equation of mass. The last equation is the first law of thermo- 
dynamics. Concerning the non-adiabatic heating $Q$, only the effect of latent heat released by cumulus convection is taken into account in this study. The stresses $\tau_{x}$ and $\tau_{y}$ may be represented as follows:

$$
\left.\begin{array}{l}
\tau_{x}=-\rho^{2} g K \frac{\partial u}{\partial p} \\
\tau_{y}=-\rho^{2} g K \frac{\partial v}{\partial p}
\end{array}\right\}
$$

and at the surface we assume

$$
\left.\begin{array}{l}
\tau_{x S}=\rho_{S} c_{D}\left|V_{S}\right| u_{S} \\
\tau_{y S}=\rho_{S} c_{D}\left|V_{S}\right| v_{S}
\end{array}\right\} \text { at } p=p_{S}
$$

where $K$ is the vertical eddy viscosity coefficient, $c_{D}$ the drag coefficient, $\rho$ the density of air and $|V|$ the horizontal wind velocity. Suffix $s$ denotes the values at the surface.

\section{2. assumptions on the heating}

As was already mentioned, when we discuss large-scale motions in the conditionally unstable atmosphere, the effect on large-scale motions of the latent heat released in a large number of cumulus clouds may be parameterized in terms of large-scale fields. Although we do not yet know detailed processes of the cumulus convection, the total amount of the latent heat released in a vertical column of air may be specified mainly by the horizontal convergence of water vapor in the friction layer because most part of the horizontal mass convergence in a tropical cyclone occurs in this layer and because most part of water vapor is included in the air of this layer. Syōno $(1944,1950)$ proposed that the rate of precipitation in a typhoon may be expressed as a product of the mixing ratio of water vapor to air and the vertical velocity at the top of the friction layer. From these considerations we may use the following assumption concerning the total amount of the released latent heat in a vertical column of air.

$$
\int Q d p=\left\{\begin{array}{cc}
-L q^{*} \omega^{*} & \left(\omega^{*}<0\right) \\
0 & \left(\omega^{*} \geqq 0\right)
\end{array}\right.
$$

where $q$ is the mixing ratio of water vapor, $L$ is the latent heat of condensation and the symbol $*$ denotes the values at the top of the friction layer. In assuming (2.4) we took into account of the fact that in cumulus clouds very rapid upward transport of the released latent heat occurs.

At present we do not know how the vertical distribution of the released latent heat $Q$ is determined. Therefore, we assume that the released heat at each level may also be proportional to the vertical $p$-velocity at the top of the friction layer, that is

$$
\frac{\theta}{c_{p} T} Q(x, p)=\left\{\begin{array}{cc}
-h(p) s(p) \omega^{*}(x) & \left(\omega^{*}<0\right) \\
0 & \left(\omega^{*} \geqq 0\right)
\end{array}\right.
$$

where $s$ is a measure of the static stability defined by $s=-\partial \theta / \partial p$, and $h$ is a dimensionless parameter and in general depends upon height. $h$ must be such that (2.4) and (2.5) are consistent. The assumption (2.5) is identical to that used by Ooyama (1963) and Ogura (1964) in their tropical cyclone model, although they did not assume the vertical distribution of heat sources explicitly. One of our interest is to investigate how the properties of disturbances is related to the vertical distribution of heat sources.

\subsection{Two different treatments of the effect of surface friction}

As is well known, the most part of the horizontal convergence in the tropical cyclone occurs in the friction layer. This is mainly due to surface friction. Ooyama (1963) and others related the vertical velocity at the top of the friction layer directly to the effect of surface friction. In this study we shall discuss two cases where the effect of surface friction is incorporated into the system in different manner.

One is the case where we incorporate surface friction into the system through the equations of motion applied to the surface. In this case, therefore, a set of equations are applied to the friction layer as well as to the free atmosphere. The surface stresses $\tau_{x s}$ and $\tau_{y s}$ are assumed to be of the form (2.3). In section 3 such a case will be discussed.

Another is the case where it is assumed that the pressure gradient force, the Coriolis force and the frictional force are always balanced in the friction layer. In this case we shall use the conventional method in which we include the effect of surface friction by imposing $\omega^{*}$ given by the formula (2.6) as a lower boundary 
condition for the motion in the free atmosphere.

$$
\omega^{*}=-c \zeta^{*}
$$

where $\zeta^{*}$ is the relative vorticity at the top of the friction layer, and $c$ is a proportional constant. The formula (2.6) is similar to that derived by Syōno (1944) and it has often been used as a conventional method in incorporating the convergence due to surface friction. In section 5 the second case will be discussed. One of our interests is to know how the properties of disturbances differ by these two different treatments of the effect of surface friction.

\section{4. derivation of perturbation equations}

We shall consider perturbations superimposed on a basic state which is under the hydrostatic equilibrium and has no flow. Letting $\Theta$ and $\Phi$ denote the potential temperature and the geopotential of isobaric surfaces of the basic state, respectively, and using the prime symbol for quantities concerning the perturbation, we have

$$
\left.\begin{array}{l}
u=u^{\prime} \\
v=v^{\prime} \\
\omega=\omega^{\prime} \\
\theta=\Theta(p)+\theta^{\prime} \\
\phi=\Phi(p)+\phi^{\prime}
\end{array}\right\}
$$

and

$$
\frac{\partial \Phi}{\partial p}=-\frac{R}{p}\left(\frac{p}{p_{0}}\right)^{R / c_{p}} \Theta
$$

where $\Theta$ and $\Phi$ are functions of pressure only, while the perturbed quantities are functions of $x, p$ and time $t$.

Introducing (2.7) into (2.1) and using the relation (2.8), we have a set of linearized perturbation equations from (2.9) to (2.13).

$$
\begin{aligned}
& \frac{\partial u^{\prime}}{\partial t}-f v^{\prime}=-\frac{\partial \phi^{\prime}}{\partial x}+\nu \frac{\partial^{2} u^{\prime}}{\partial x^{2}}-g \frac{\partial \tau_{x}}{\partial p} \\
& \frac{\partial v^{\prime}}{\partial t}+f u^{\prime}=\nu \frac{\partial^{2} v^{\prime}}{\partial x^{2}}-g \frac{\partial \tau_{y}}{\partial p} \\
& \frac{\partial \phi^{\prime}}{\partial p}=-B \theta^{\prime} \\
& \frac{\partial u^{\prime}}{\partial x}+\frac{\partial \omega^{\prime}}{\partial p}=0
\end{aligned}
$$

$$
\frac{\partial \theta^{\prime}}{\partial t}-S \omega^{\prime}=\frac{\Theta}{c_{p} T} Q+\kappa \frac{\partial^{2} \theta^{\prime}}{\partial x^{2}}
$$

where

$$
B \equiv-\frac{R}{p}\left(\frac{p}{p_{0}}\right)^{R / c_{p}}
$$

$S$ is a measure of the static stability of the basic state defined by

$$
S \equiv-\frac{\partial \Theta}{\partial p}
$$

In (2.9) and (2.10) $\tau_{x}$ and $\tau_{y}$ are expressed by (2.2) and (2.3), but at this time $|V|$ is considered to be constant. Hereafter we shall omit the prime symbol denoting the perturbation quantities.

\section{5. a three-layer representation}

For mathematical simplicity we shall use' a three-layer model, which is shown in Fig. 1.

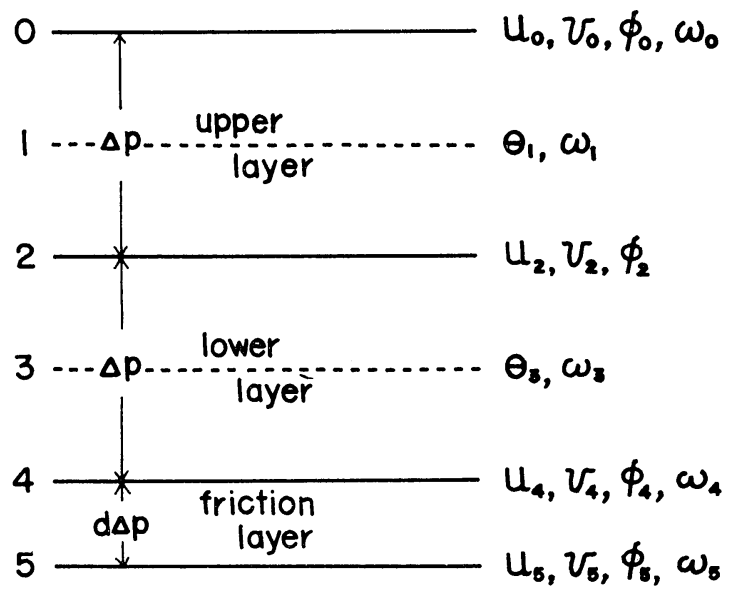

Fig. 1. Layer model and levels at which variables are defined.

The lowest layer [4-5] corresponds to the friction layer in the atmosphere. The free atmosphere is divided into two layers: the upper layer [0-2], and the lower layer [2-4], in order to investigate the effect of the vertical partition of the released latent heat of condensation. The levels at which five dependent variables are defined are also shown in Fig. 1.

We shall adopt the following boundary conditions.

$$
\left.\begin{array}{l}
\omega_{0}=0 \\
\omega_{5}=0
\end{array}\right\}
$$

Concerning the potential temperature in the 
friction layer [4-5] we shall assume no horizontal variation of the potential temperature, namely

$$
\frac{\partial \theta}{\partial x}=0
$$

In actual tropical cyclones the above assumption is not valid. It has been shown that the sensible and latent heat transfer from the ocean surface is very important in the tropical cyclone (Malkus and Riehl, 1960). However, in order to clarify the effect of latent heat released by cumulus convection, we shall not include the non-adiabatic processes at the surface. The assumption (2.17) leads to

$$
\frac{\partial \phi_{4}}{\partial x}=\frac{\partial \phi_{5}}{\partial x}
$$

Now we shall apply the equations of motion (2.9) and (2.10) to levels $0,2,4$ and 5. The hydrostatic equation (2.11) and the thermodynamic equation (2.13) will be applied to levels 1 and 3 , and the equation of continuity (2.12) to layers [0-1], [1-3], [3-4] and [4-5]. In this case the mean horizontal divergence in layer [0-1] will be approximately expressed by $\partial u_{0} / \partial x$, in layer [1-3] by $\partial u_{2} / \partial x$, in layer [3-4] by $\partial u_{4} / \partial x$ and in layer [4-5] by $\frac{1}{2}\left[\frac{\partial u_{4}}{\partial x}\right.$ $\left.+\frac{\partial u_{5}}{\partial x}\right]$. By the use of (2.16) and (2.18) a set of equations for sixteen variables $u_{i}, v_{i}$ $(i=0,2,4,5), \phi_{i}(i=0,2,4), \omega_{i}(i=1,3,4)$ and $\theta_{i}(i=1,3)$ will be given by $(2.19 \mathrm{a}) \sim(2.19 \mathrm{~h})$,

$$
\begin{aligned}
& \frac{\partial u_{i}}{\partial t}-f v_{i}=-\frac{\partial \phi_{i}}{\partial x}+\nu \frac{\partial^{2} u_{i}}{\partial x^{2}} \quad(i=0,2,4) \\
& \frac{\partial u_{5}}{\partial t}-f v_{5}=-\frac{\partial \phi_{4}}{\partial x}+\nu \frac{\partial^{2} u_{5}}{\partial x^{2}}-D u_{5} \\
& \frac{\partial v_{i}}{\partial t}+f u_{i}=\nu \frac{\partial^{2} v_{i}}{\partial x^{2}} \quad(i=0,2,4) \\
& \frac{\partial v_{5}}{\partial t}+f u_{5}=\nu \frac{\partial^{2} v_{5}}{\partial x^{2}}-D v_{5} \\
& \frac{\partial \theta_{i}}{\partial t}-S_{i} \omega_{i}=\frac{\Theta_{i}}{c_{p} T_{i}} Q_{i}+\kappa \frac{\partial^{2} \theta_{i}}{\partial x^{2}} \quad(i=1,3) \\
& \frac{\phi_{i+1}-\phi_{i-1}}{\Delta p}=-B_{i} \theta_{i} \quad(i=1,3)
\end{aligned}
$$

$$
\left.\begin{array}{c}
\frac{\partial u_{0}}{\partial x}+\frac{\omega_{1}}{\Delta p / 2}=0 \\
\frac{\partial u_{2}}{\partial x}+\frac{\omega_{3}-\omega_{1}}{\Delta p}=0 \\
\frac{\partial u_{4}}{\partial x}+\frac{\omega_{4}-\omega_{3}}{\Delta p / 2}=0
\end{array}\right\}
$$

where $D$ represents the effect of surface friction and is defined by

$$
D \equiv \frac{2 c_{D}|V|}{d \Delta p} \rho_{5} g
$$

$\Delta p$ is the depth (in milibar) of layers [0-2] and [2-4] and $d$ is a measure of the depth of the friction layer [4-5]. (See Fig. 1) In deriving (2.19), we omitted the effect of the vertical eddy viscosity because the inclusion of this effect will make the following perturbation analysis very complicated. The vertical eddy viscosity does not seem to change the characteristic features of disturbances. Moreover, we shall confine discussions to the case when the Prandtl number $\nu / \kappa$ is unity.

$Q_{1}$ and $Q_{3}$ in $(2.19 \mathrm{e})$ are the amount of the released latent heat given to the air of unit mass per unit time in the upper layer and in the lower layer, respectively, and they are given by the assumption (2.5) as follows:

$$
\left.\begin{array}{c}
\frac{\Theta_{1}}{c_{p} T_{1}} Q_{1}=-\eta S_{1} \omega_{4} \\
\frac{\Theta_{3}}{c_{p} T_{3}} Q_{3}=-\xi S_{3} \omega_{4}
\end{array}\right\}
$$

where $S_{1}$ and $S_{3}$ are the static stability of the basic state defined by (2.15), $\omega_{4}$ is the vertical $p$-velocity at level 4 , and $\xi$ and $\eta$ are dimensionless parameters. If all the amount of water vapor included in the air ascending through the top of the friction layer is assumed to be condensed in the vertical column, $\xi$ and $\eta$ are related to $q$ (the mixing ratio of water vapor to the ascending air through level 4) as the following:

$$
c_{p} \Delta p\left(\frac{T_{1} S_{1}}{\Theta_{1}} \eta+\frac{T_{3} S_{3}}{\Theta_{3}} \xi\right)=L q
$$

Letting $l$ represent the ratio of the amount of 
the latent heat released in the lower layer to the total amount of the latent heat released in the vertical column of air, in other words defining $l$ by

$$
l \equiv \frac{Q_{3}}{Q_{1}+Q_{3}}
$$

then we have

$$
\frac{\xi}{\eta}=\frac{\Theta_{3} T_{1} S_{1}}{\Theta_{1} T_{3} S_{3}} \frac{l}{1-l}
$$

In the following perturbation analysis we shall use $\xi$ and $\eta$ as parameters concerning the heating. However, by the use of the relations (2.22) and (2.24) the values of $q$ and $l$ corresponding to some values of $\xi$ and $\eta$ are easily known.

If the vertical motion at the top of the friction layer is downward, namely $\omega_{4}>0$, it is appropriate to set $\xi$ and $\eta$ be zero. However, in the perturbation analysis, for simplicity, we assume that (2.21) is valid also for $\omega_{4}>0$. We shall refer such a case to the unconditional heating case. $\xi$ and $\eta$ are treated as constant parameters. In section 6 some numerical calculations for both the unconditional heating case and the conditional heating case (we set $\xi=\eta=0$ if $\omega_{4}>0$ ) will be carried out and results for both cases will be compared.

In the balanced model discussed in section 5 we shall use the following formula (2.25) instead of (2.19b), (2.19d) and (2.19h).

$$
\omega_{4}=-c \frac{\partial v_{4}}{\partial x}
$$

\section{Stability of perturbations in the unbal- anced model}

Ooyama (1963) and others found a disturbance with the growth rate and the preferred scale comparable to those observed in tropical cyclones by using the balanced model. On the other hand in our earlier numerical experiments with the use of primitive equations (Syōno and Matsuno, 1963), an amplifying oscillatory wave was found. Such a wave was not found in the balanced model by Ooyama and others.

Our first interest is to find out the condition under which such an amplifying oscillatory wave exists. Our another and main interest is whether or not we can obtain a disturbance similar to tropical cyclones by using the unbalanced model. In this section we do not assume the balance between the pressure and the wind in the free atmosphere, thus we retain $\partial u / \partial t$ in (2.19a). Moreover, at level 5 we shall deal with the equations of motion, $(2.19 \mathrm{~b})$ and (2.19d) including the surface stress terms.

3.1. derivation of the frequency equation

Assuming the solution of the form $e^{i k(x-c t)}$ for each variable in (2.19), we have a set of homogeneous equations (3.1) for the complex amplitude $U_{i}(i=0,2,4,5)$ of $u_{i}$, the $x$-component of the horizontal wind.

$$
\text { (A) }\left(\begin{array}{c}
U_{0} \\
U_{2} \\
U_{4} \\
U_{5}
\end{array}\right)=0
$$

where

$$
\begin{aligned}
& \text { (A) } \\
& \equiv\left(\begin{array}{cccc}
1 & 2 & d+1 & d \\
0 & 0 & -r(X+D) & \left\{(X+D)^{2}+f^{2}\right\} X \\
-2 r & 2 r+2 M_{1} & M_{1}-H_{1} & -H_{1} \\
0 & -2 r & 2 r+M_{3}-H_{3} & -H_{3}
\end{array}\right) \\
& X \equiv-i k c+\nu k^{2} \\
& r \equiv X^{2}+f^{2} \\
& M_{1} \equiv k^{2}(\Delta p)^{2} B_{1} S_{1} \\
& M_{3} \equiv k^{2}(\Delta p)^{2} B_{3} S_{3} \\
& H_{1} \equiv d(\eta-1) M_{1} \\
& H_{3} \equiv d(\xi-1) M_{3}
\end{aligned}
$$

$k$ is the horizontal wave number of a sinusoidal perturbation, $c$ is the phase velocity which is a complex number in general i.e., $c=c_{r}+i c_{i}$, and $D$ represents the effect of surface friction as defined by (2.20). The frequency equation is derived from the condition that $U_{i}(i=0,2$, $4,5)$ have non-zero solutions, namely

$$
|A|=0
$$

This frequency equation is an equation of the seventh degree with respect to $X\left(=-i k c+\nu k^{2}\right)$. The growth rate $\sigma$ and the phase velocity $c_{r}$ of a perturbation are given by $\sigma=R_{e}(X)-\nu k^{2}$ and $c_{r}=-I_{m}(X) / k$, respectively. 


\section{2. solutions of the frequency equation}

(a) the case without surface friction

In the case of no surface friction the frequency equation (3.4) is written in the following form by setting $D=0$.

$$
X\left(X^{2}+f^{2}\right)\left(P X^{4}+Q X^{2}+R\right)=0
$$

where

$$
\begin{aligned}
P= & -4(d+2) \\
Q= & -8(d+2) f^{2} \\
& +3 k^{2}(\Delta p)^{2} B_{3} S_{3}\{2 d(\xi-1)-1\} \\
& +k^{2}(\Delta p)^{2} B_{1} S_{1}\{2 d(\eta-1)-3\} \\
R= & -4(d+2) f^{4} \\
& +k^{4}(\Delta p)^{4} B_{1} B_{3} S_{1} S_{3}\{2 d(\xi-1)-1\} \\
& +3 f^{2} k^{2}(\Delta p)^{2} B_{3} S_{3}\{2 d(\xi-1)-1\} \\
& +f^{2} k^{2}(\Delta p)^{2} B_{1} S_{1}\{2 d(\eta-1)-3\}
\end{aligned}
$$

One of the seven solutions gives $X=0$. This solution represents a disturbance which is in complete geostrophic balance. Two solutions obtained from $X^{2}+f^{2}=0$ correspond to purely inertial oscillations. Since no horizontal variation of the potential temperature in the friction layer is assumed, pure inertial oscillations are obtained when the effect of surface friction is omitted. The other solutions are obtained by setting the third blanket in (3.5) be zero.

$$
P X^{4}+Q X^{2}+R=0
$$

Solutions of (3.7) represent inertial gravity oscillations or waves modified by heating as seen from (3.6).

Parameters included in equation (3.7) are $d, f, \Delta p, B_{1}, B_{3}, S_{1}, S_{3}$ and $k$ together with $\xi$ and $\eta$. In this study the values of the parameters except $\xi$ and $\eta$ will be chosen as follows:

$$
\begin{array}{ll}
d=1 / 3 & S_{1}=0.08^{\circ} \mathrm{K} \mathrm{mb}^{-1} \\
f=5 \times 10^{-5} \mathrm{sec}^{-1} & S_{3}=0.06^{\circ} \mathrm{K} \mathrm{mb}^{-1} \\
\Delta p=350 \mathrm{mb} & B_{1}=0.58 \mathrm{~m}^{2} \mathrm{sec}^{-2} \mathrm{mb}^{-1}{ }^{\circ} \mathrm{K}-1 \\
& B_{3}=0.36 \mathrm{~m}^{2} \mathrm{sec}^{-2} \mathrm{mb}^{-1}{ }^{\circ} \mathrm{K}^{-1}
\end{array}
$$

The above values of $B_{1}$ and $B_{3}$ correspond to

$$
\begin{array}{ll}
P_{1}=375 \mathrm{mb} & R=287 \mathrm{~m}^{2} \mathrm{sec}^{-2}{ }^{\circ} \mathrm{K}^{-1} \\
P_{3}=725 \mathrm{mb} & c_{p}=0.24 \mathrm{cal} \mathrm{g}^{-1}{ }^{\circ} \mathrm{K}^{-1}
\end{array}
$$

The properties of disturbances corresponding to the solutions of (3.7) vary depending upon the values of $\xi$ and $\eta$ (Fig. 2). As defined by (2.21), $\xi$ is a parameter determining the heating in the lower layer and $\eta$ is that in the upper layer.

In domain I where $\xi$ is smaller than about 2.5 and $\eta$ is also relatively small, any amplifying waves do not exist, while in domains II, III and IV there exist amplifying waves. The amplifying waves which exist in domain III and IV are stationary ones whose phase velocity is zero. (It should be mentioned that the values of $\xi$ and $\eta$ corresponding to domain IV are unrealistic. $\xi$ and $\eta$ are related to $q$, the mixing ratio of water vapor to ascending air, as shown in (2.22) and the value of $q$ has an upper limit in the atmosphere. The values of $\xi$ and $\eta$ seem to be at most 5.)

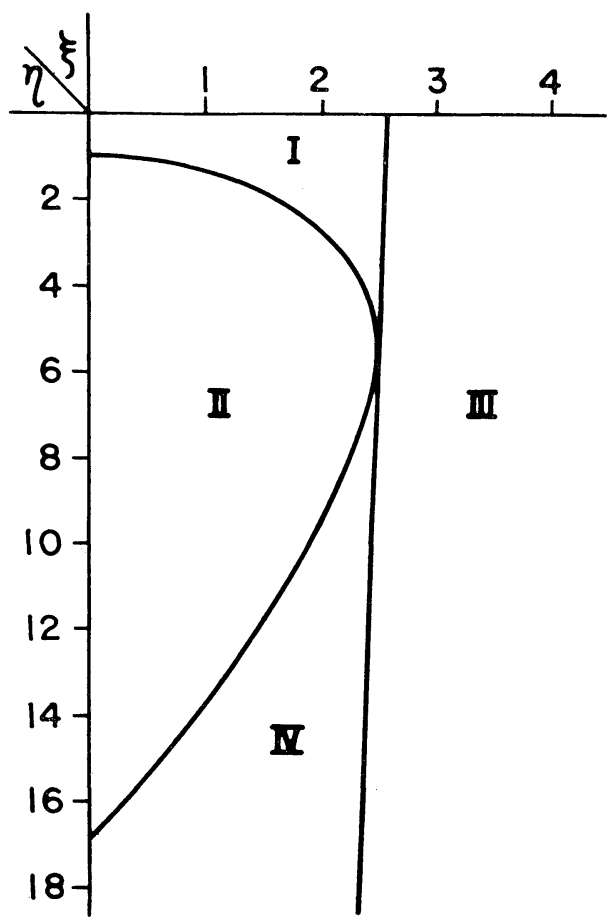

Fig. 2. Four domains dividing the properties of waves for the case without the surface friction expressed in $\xi-\eta$ space (for $\nu=0$ ). In domain I there exist two sets of neutral propagating waves, in domain II a set of amplifying propagating waves and a set of damping propagating waves, in domain III an amplifying and a damping stationary waves and a set of neutral propagating waves and in domain IV two types of amplifying stationary waves and two types of damping stationary waves. 


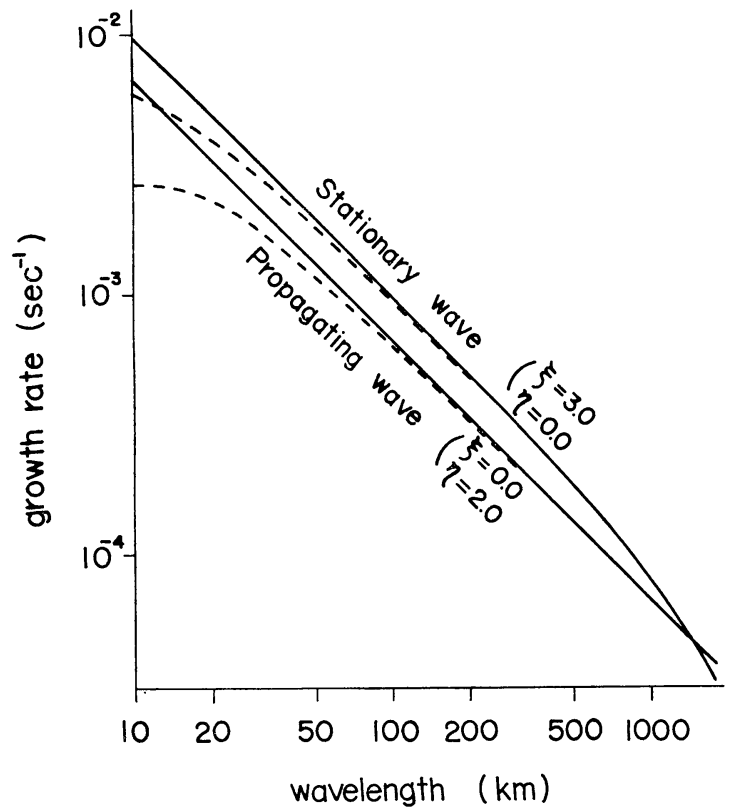

Fig. 3. The growth rate of amplifying propagating wave in domain II and that of amplifying stationary wave in domain III as functions of the horizontal wavelength. Both the ordinate and the abscissa are taken in the logarithmic scale. The solid lines are drawn for non-viscous cases and the dotted lines for $\nu=10^{4} \mathrm{~m}^{2} \mathrm{sec}^{-1}$.

We shall investigate the properties of each solution more in detail. In Fig. 3 the growth rate of the amplifying propagating wave in domain II and that of the amplifying stationary wave in domain III are shown as functions of the horizontal wavelength. The growth rate of the amplifying propagating wave is shown for $\xi=0.0$ and $\eta=2.0$, and that of the amplifying stationary wave for $\xi=3.0$ and $\eta=$ 0.0. The solid lines are drawn for the nonviscous case, while the dotted lines are for $\nu=10^{4} \mathrm{~m}^{2} \mathrm{sec}^{-1}$. As is seen from Fig. 3 amplifying propagating waves in domain II have very large growth rates which are in the order of magnitude $10^{-3} \sim 10^{-2} \mathrm{sec}^{-1}$ for waves whose horizontal wavelength are smaller than $100 \mathrm{~km}$ and its preferred horizontal scale is about 10 $\mathrm{km}$. Amplifying stationary waves in domain III have similar features with respect to the growth rate and the preferred scale. The growth rate of amplifying propagating waves increases with $\eta$ and decreases with $\xi$. On the other hand the growth rate of amplifying stationary waves increases with $\xi$ and with $\eta$.
The phase velocity of amplifying propagating waves in domain II is about $30-40 \mathrm{~m} / \mathrm{sec}$ when $\eta$ is not so large. In domain I there exist two types of neutral propagating waves which are different in their phase velocities. The difference between the phase velocities of two different types of the propagating waves becomes smaller as $\eta$ is increased and it becomes zero on the boundary of domain I and II shown in Fig. 2. In other words two types of solutions of equation (3.7) merge together on the boundary of domains I and II, and in domain II they are separated into amplifying propagating waves and damping ones with the same phase velocity.

(b) the case including surface friction

In this case the frequency equation (3.4) are written as follows:

$$
\sum_{i=0}^{7} P_{i} X^{i}=0
$$

where

$$
\begin{aligned}
P_{7}= & 4(d+2) \\
P_{6}= & (6 d+16) D \\
P_{5}= & 2(d+4) D^{2}+12(d+2) f^{2} \\
& +\left(3 M_{1}-2 H_{1}+3 M_{3}-6 H_{3}\right) \\
P_{4}= & (14 d+32) D f^{2} \\
& +\left(6 M_{1}-3 H_{1}+6 M_{3}-9 H_{3}\right) D \\
P_{3}= & 12(d+2) f^{4}+\left(6 M_{1}-4 H_{1}+6 M_{3}-12 H_{3}\right) f^{2} \\
& +4(d+4) D^{2} f^{2}+\left(3 M_{1}-H_{1}+3 M_{3}-3 H_{3}\right) D^{2} \\
& +M_{1}\left(M_{3}-2 H_{3}\right) \\
P_{2}= & (10 d+16) D f^{4} \\
& +\left(6 M_{1}-4 H_{1}+6 M_{3}-12 H_{3}\right) D f^{2} \\
& +M_{1}\left(2 M_{3}-3 H_{3}\right) D \\
P_{1}= & 2(d+4) D^{2} f^{4}+\left(3 M_{1}-H_{1}+3 M_{3}-3 H_{3}\right) D^{2} f^{2} \\
& +M_{1}\left(M_{3}-H_{3}\right) D^{2}+4(d+2) f^{6} \\
& +\left(3 M_{1}-2 H_{1}+3 M_{3}-6 H_{3}\right) f^{4} \\
& +M_{1}\left(M_{3}-2 H_{3}\right) f^{2} \\
P_{0}= & 2 d D f^{6}-\left(H_{1}+3 H_{3}\right) D f^{4}-M_{1} H_{3} D f^{2}
\end{aligned}
$$

Equation (3.8) are solved only numerically. The value of $D$ is taken equal to $8.6 \times 10^{-6} \mathrm{sec}^{-1}$.

We shall discuss the properties of solutions of equation (3.8) compared with the case without surface friction. Our concern is how the solutions obtained in the frictionless case are 
modified by including surface friction.

1) amplifying propagating wave in domain II

The growth rate of this wave becomes smaller by including the surface friction, but the difference is at most $0.5 \%$ for waves whose horizontal wavelength is smaller than $1,000 \mathrm{~km}$. The phase velocity is also not affected by the inclusion of surface friction. The effect of surface friction appears to be negligibly small for this wave.

2) amplifying stationary wave in domains III and IV

The surface friction has a very small effect also on this wave. The decrease of the growth rate of this wave is within $1 \%$ for shorter waves whose wavelength is smaller than $100 \mathrm{~km}$.

3) modification of neutral stationary wave by surface friction

In the case of not including the surface friction we found the solution $X=0$, which represents a disturbance in geostrophic balance. This solution is modified by including the surface friction and we obtain a solution corresponding to an amplifying or damping stationary wave depending upon values of $\xi$ and $\eta$. Fig. 4 shows that this stationary wave is amplified in domain $B$ and is damped in domains $A$ and III (for $\nu=0$ ).

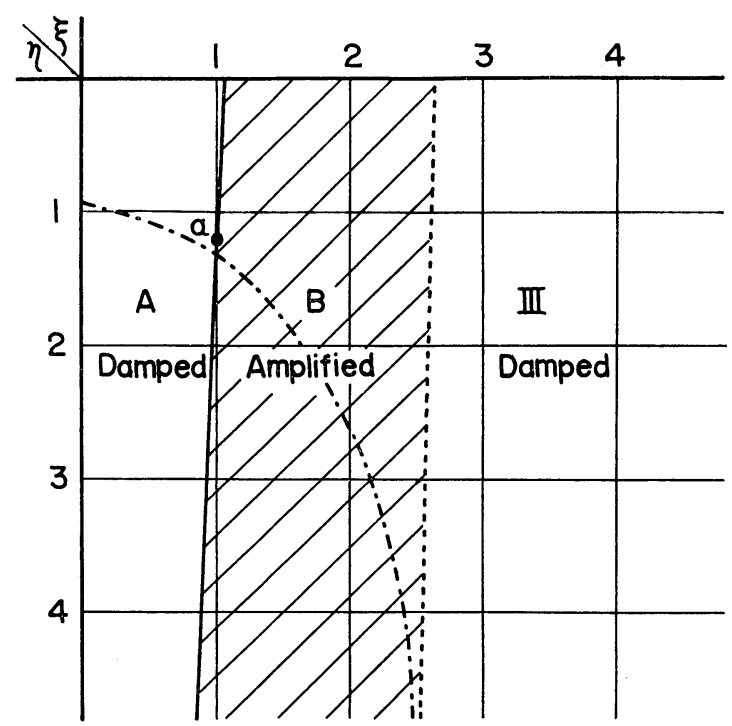

Fig. 4. The shaded area shows the domain where a neutral stationary wave is amplified by including surface friction (for $\nu=0$ ). The dotted line divides domain I and domain III and the dashed line divides domain I and domain II (See Fig. 2). ' $a$ ' shows the point at which the line dividing domain $A$ and $B$ intersects the line $\xi=1.0$.

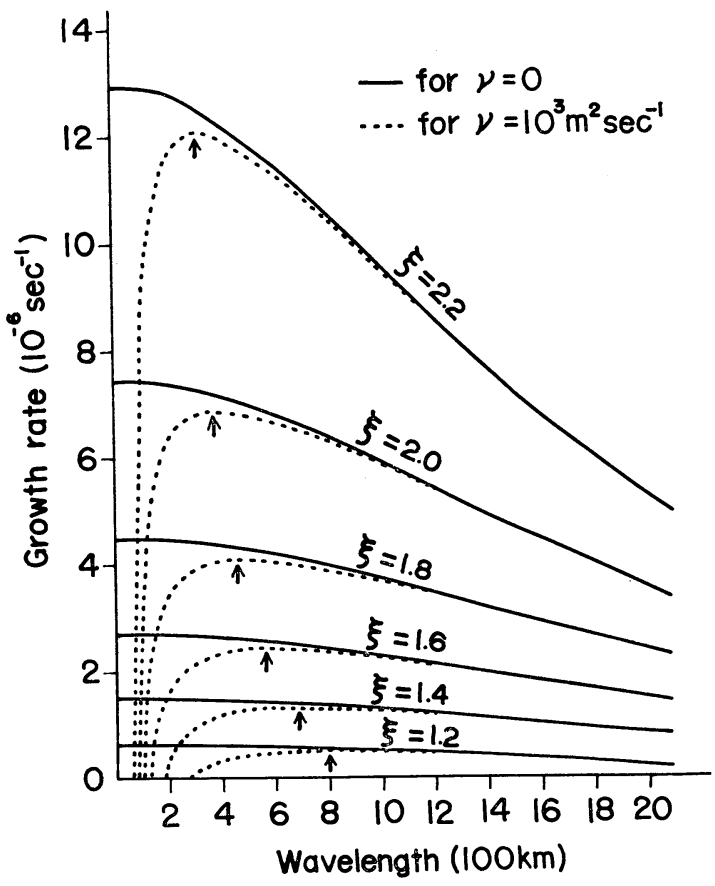

Fig. 5. The growth rate of amplifying stationary waves in domain $B$ when $\eta=0$ as a function of the horizontal wavelength for various values of $\xi$. The solid lines are drawn for non-viscous cases and the dotted lines for $\nu=10^{3} \mathrm{~m}^{2} \mathrm{sec}^{-1}$.

The relation between the growth rate and the horizontal wavelength of the amplifying stationary wave in domain $B$ is shown in Fig. 5 . The solid lines are for the non-viscous case and the dotted lines for $\nu=10^{3} \mathrm{~m}^{2} \mathrm{sec}^{-1}$. The amplifying stationary wave in domain $B$ has the growth rate which is in the order of magnitude $10^{-6} \sim 10^{-5} \mathrm{Sec}^{-1}$, and the preferred horizontal scale is several hundred kilometers for $\nu=10^{3} \mathrm{~m}^{2} \mathrm{sec}^{-1}$. The growth rate of this stationary wave increases with $\xi$ and with $\eta$. Particularly the growth rate sensitively depends upon $\xi$. In Fig. 5 the growth rate curves are drawn for $\eta=0$.

4) modification of neutral propagating waves As already shown in Fig. 2 there exist two types of neutral propagating waves in domain I and only one type of neutral wave in domain III. These waves are also modified by the surface friction and are amplified or damped depending upon values of $\xi$ and $\eta$. The growth rate of amplifying propagating waves of this type is comparable to or- one order of magnitude smaller than that of the amplifying stationary wave in domain $B$. 
5) modification of pure inertial oscillatory waves

When there is no surface friction this wave is neutral. By including surface friction this wave is amplified only in domain III. However, the growth rate is much smaller than that of the amplifying stationary wave in domain III.

\section{3. discussion}

In this sub-section some physical interpretations of the main results obtained in the previous sub-section will be given.

(a) unstable gravity waves in domain III

The amplifying stationary wave found in domain III is a kind of unstable gravity waves, whose growth rate is large and preferred horizontal scale is small. The waves are similar to those found by Haque (1952), Syōno (1953), Lilly (1960), Kuo (1961) and Yanai (1961b) from linear theories and those which appeared in early numerical calculations carried out by Kasahara (1961) and Syōno (1962). It is notew rrthy that we obtained these unstable gravity waves in spite of the use of heating assumption (2.21) which is different from the assumptions they used.

The unstable gravity waves are found for the condition $\xi \gtrsim 2.5$ in our model. In the case of no surface friction, $\xi \geqslant 2.5$ gives the condition that the temperature in the lower layer of the ascending region is increased. The warming in the lower layer causes the drop of the pressure in the lowest layer [4-5] and induces more horizontal convergence. Thus the ascending motion becomes stronger and disturbances develop. The horizontal convergence in this type of disturbance is caused by the allobaric effect. The surface friction acts rather to suppress the horizontal convergence in the surface layer, but the effect is very small.

(b) nearly neutral or slightly amplifying gravity oscillations in domain I

In the case of no surface friction, for $\xi \leq 2.5$ and for a small value of $\eta$ in domain I, there exist only neutral gravity oscillatory waves. In this case the adiabatic cooling due to the upward motion is larger than the warming due to the released heat in the ascending region because the relatively small amount of heat is released both in the upper layer and in the lower layer, while in the descending region it becomes warmer. In the case of including the surface friction the neutral gravity oscillations are modified into the amplifying or damping ones, although the growth rate is very small compared with the unstable gravity waves in domain III.

(c) amplifying gravity oscillations in domain II

For a relatively large value of $\eta$ in domain II the temperature in the upper layer of the ascending region tends to increase due to the relatively large amount of released heat, while in the lower layer the cooling occurs. In this domain the effect of the cooling in the lower layer is larger than that of the warming in the upper layer, so that the surface pressure in the ascending region becomes higher and the decrease of the horizontal convergence in layer [4-5] causes the decrease of the amount of the released heat in the column. Thus the temperature in the upper layer cannot continue to increase and tends to decrease soon. In a neutral oscillatory wave the change of the vertical motion has the phase lag $\pi / 2$ to the temperature change. On the other hand in this wave the phase lag is smaller than $\pi / 2$. In other words the correlation between the vertical $p$-velocity and the perturbed part of the potential temperature is negative, so that the conversion from the potential energy to the kinetic energy of waves occurs. For such a reason the propagating waves existing in domain II are amplified. This wave is a kind of unstable gravity wave modified by heating. Since the preferred horizontal scale of the amplifying wave is several ten kilometers and the phase velocity is about $30-40 \mathrm{~m} / \mathrm{sec}$, the period of oscillations is smaller than one hour.

The amplifying gravity oscillatory waves are similar to those which appeared in a numerical calculation carried out by Syōno and Matsuno. In the numerical calculation the vertical partition of the released heat assumed was equivalent to the case when $75 \%$ of the total amount of the released heat is given to the upper layer and the remainder is given to the lower layer in the present model.

We do not know whether in the real atmosphere such amplifying gravity oscillations exist. This type of amplifying waves might have been obtained rather artificially by the assumption concerning the heating (2.21). If 
we parameterize the effect of cumulus clouds on the large scale motion in a different way from (2.21), such waves may not be found. (d) unstable gravity waves in domain IV

For a very large value of $\eta$ in domain IV the warming in the upper layer is larger than the cooling in the lower layer of the ascending region. Thus the surface pressure is lowered and the horizontal convergence in the layer [4-5] is continuously increased. Therefore in this case a stationary wave instead of a propagating wave is amplified. In our two layer model of the free atmosphere $\eta$ cannot take such a large value as contained in domain IV.

(e) gradually growing disturbances of typhoon-scale in domain $B$

It is very interesting that when we include the effect of surface friction, we have a new type of amplifying stationary wave in domain $B(1.0 \leqq \xi \leqq 2.5)$ as shown in Fig. 4. The growth rate of this wave is in the order of magnitude $10^{-6} \sim 10^{-5} \mathrm{sec}^{-1}$ and the preferred horizontal scale is several hundred kilometers for $\nu=10^{3} \mathrm{~m}^{2} \mathrm{sec}^{-1}$. Both the growth rate and the horizontal scale are comparable to those of actual tropical cyclones. This wave is similar to that obtained by Ooyama (1963), Charney and Eliassen (1964) and Ogura (1964). They assumed the geostrophic (or gradient wind) balance in the free atmosphere and they further assumed the balance among the pressure gradient force, the Coriolis force and the frictional force in the friction layer. On the other hand we have obtained this solution by using the primitive equations of motion in the horizontal direction both in the free atmosphere and in the friction layer. It is noteworthy that the existence of this typhoon-scale amplifying wave is due to the surface friction. When there is no surface friction, this disturbance is reduced to a neutral stationary motion in geostrophic balance.

It should be noted that the growth rate of this disturbance increases monotonously as $\xi$ increases from about 1.0 to 2.5 , but such a type of amplifying disturbance does not exist for $\xi \geq 2.5$. As already shown, for $\xi \geq 2.5$ (domain III) unstable gravity waves grow very rapidly.If we specify $\omega_{4}$ by the formula (2.25) as used by Ooyama and others, it will be shown in section 5 that this situation is largely modified. The unstable gravity waves existing for $\xi \geq 2.5$ are eliminated and the typhoon-scale disturbance can exist provided $\xi \geq 1.0$.

As was already mentioned, neutral gravity oscillations in domain I in the frictionless case are amplified or damped by including the surface friction. Unfortunately, they are possibly amplified in domain IB (defined as the common domain of domain I and domain B) where a typhoon-scale disturbance develops. The growth rate of such amplifying gravity oscillatory waves is comparable to or is an order of magnitude smaller compared to that of typhoon-scale disturbance. If we carry out a numerical calculation for domain IB using the unconditional heating, gravity oscillations will be amplified together with developing typhoonscale disturbances. In section 6 it will be shown that the amplifying gravity oscillations superimposed upon a typhoon-scale disturbance is removed when we adopt the conditional heating. However, gravity oscillation existing in domain II is amplified with the very large growth rate even in such a case. Therefore, we cannot simulate the development of a tropical cyclone for domain IIB (defined as the common domain of domain II and domain B), unless we filter out the amplifying gravity oscillation.

\section{(f) discussion in terms of $q$ and $l$}

We shall show the condition under which various types of disturbances exist, in terms of $q$ and $l$ instead of $\xi$ and $\eta$, where $q$ is mixing ratio of water vapor to the ascending air through level 4 , and $l$ is the ratio of the amount of heat released in the lower layer to the total amount of heat released in the vertical column of air. From (2.22) and (2.24) we see that in the transformation of $\xi$ and $\eta$ into $q$ and $l$ the static stability of the basic state is an important parameter. We shall use the same values of $S_{1}$ and $S_{3}$ as chosen previously.

$$
S_{1}=0.08^{\circ} \mathrm{K} \mathrm{mb}^{-1} \text { and } S_{3}=0.06^{\circ} \mathrm{K} \mathrm{mb}^{-1} \text {. }
$$

Fig. 6 shows only the disturbances which are predominant in each domain. $q$ is taken as ordinate and $l$ as abscissa. Domain IV shown in Fig. 2 does not appear in this diagram because the value of $q$ corresponding to domain IV is unrealistically large.

The results obtained in this section will be summarized using two parameters $q$ and $l$ as follows. For different values of $q$ and $l$ the 


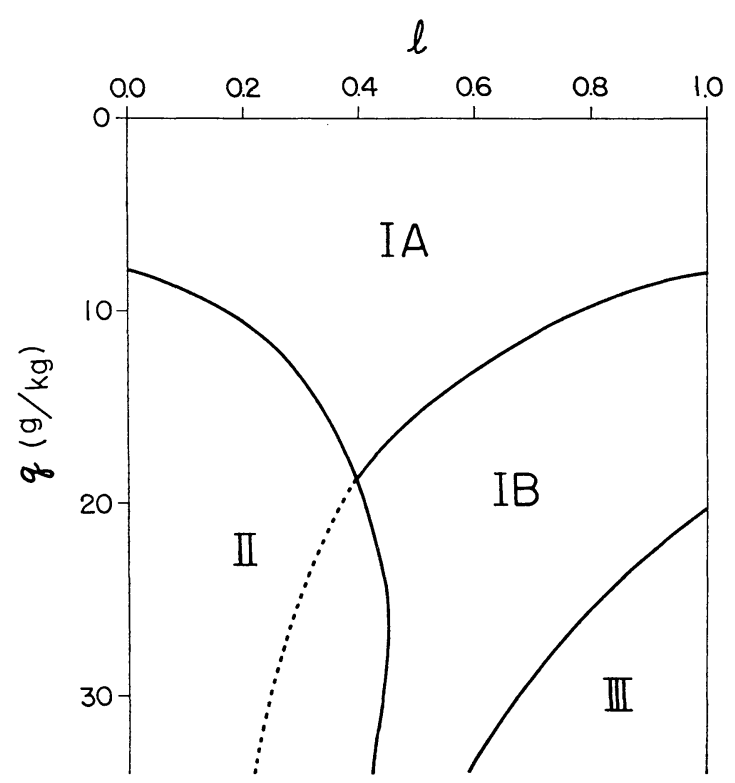

Fig. 6. Four domains dividing properties of predominant disturbances in the unbalanced model expressed in $q-l$ space. In domain IA nearly neutral gravity oscillations are found and any stationary waves are damped, in domain IB a tophoon-scale disturbance develops gradually, in domain II short-period gravity oscillations are amplified, and in domain III small-scale disturbances grow very rapidly.

following four cases may occur.

1) When $q$ is relatively small (domain IA) there exist nearly neutral gravity oscillations. Under such conditions stationary waves are damped.

2) When $q$ is not so small and the larger part of heat is released in the upper layer (domain II), small-period and small-scale gravity oscillations are amplified.

3) When $q$ is relatively large and the most part of heat is released in the lower layer (domain III), a small scale disturbance grows very rapidly. This is essentially an unstable gravity wave.

4) For the appropriate values of $q$ and $l$ (domain IB), the typhoon-scale disturbance develops gradually. In addition gravity oscillations are also amplified with the growth rate comparable to that of typhoon-scale disturbance for the unconditional heating case.

It should be noted that since the growth rate of the typhoon-scale disturbance becomes larger with $\xi$ (and $\eta$ ), the growth rate increases with $q$ and with $l$ and decreases with the static stability $S_{3}$ (and with $S_{1}$ ), as seen from (2.22) and (2.24).

\section{Structures of the typhoon-scale distur- bance}

In the previous section it was shown that we can obtain the typhoon-scale disturbance for domain IB in the $\xi-\eta$ diagram (or $q-l$ diagram). The growth rate and the preferred horizontal scale were already shown, so that in this section we shall show some structures of the disturbance. For this purpose we shall seek for the eigen solutions of the $x$-component of wind $u$ and the potential temperature $\theta$. The expressions for the amplitude $U$ of $u$ are derived from (3.1), provided $U_{5}$ is given.

$$
\left.\begin{array}{l}
U_{4}=\frac{\left\{(X+D)^{2}+f^{2}\right\} X}{\left(X^{2}+f^{2}\right)(X+D)} U_{5} \\
U_{2}=\frac{\left(2 X^{2}+2 f^{2}+M_{3}-H_{3}\right) U_{4}-H_{3} U_{5}}{2\left(X^{2}+f^{2}\right)} \\
U_{0}=-2 U_{2}-(d+1) U_{4}-d U_{5}
\end{array}\right\}
$$

The amplitudes $\theta_{a 1}$ and $\theta_{a 3}$ of the perturbation potential temperature $\theta_{1}$, and $\theta_{3}$ are written using $u_{i}$ :

$$
\left.\begin{array}{l}
\theta_{a 1}=\frac{i k \Delta p S_{1}}{2 X}\left\{d(1-\eta)\left(U_{4}+U_{5}\right)+U_{4}+2 U_{2}\right\} \\
\theta_{a 3}=\frac{i k \Delta p S_{3}}{2 X}\left\{d(1-\xi)\left(U_{4}+U_{5}\right)+U_{4}\right\}
\end{array}\right\}
$$

The structures of typhoon-scale disturbances over half a wavelength are illustrated for four combinations of $\xi$ and $\eta$ in Figs. $7 \mathrm{a}-7 \mathrm{~d}$. In each case $U_{5}$ is chosen so as to satisfy $\theta_{a 1}+\theta_{a 3}$ $=1$. The solid lines show the geopotential of isobaric surfaces and the dotted lines are streamlines. Fig. $7 \mathrm{a}$ is the case corresponding to $q=18.5 \mathrm{~g} / \mathrm{kg}$ and $l=0.83$, namely $83 \%$ of the amount of the released heat is given to the lower layer. In this case we get a warming in the lower layer and a cooling in the upper layer of the ascending region. Fig. $7 \mathrm{~b}$ shows the case when the warming in the lower layer is larger than that in the upper layer, while Fig. $7 \mathrm{c}$ is for the case when the warming in the upper layer is larger than that in the lower layer. Fig. $7 \mathrm{~b}$ corresponds to $l=0.63$, and Fig. $7 \mathrm{c}$ to $l=0.48$. It should be noted that in the case shown in Fig. 7c the vertical partition rate of heat in the upper layer and that in the 


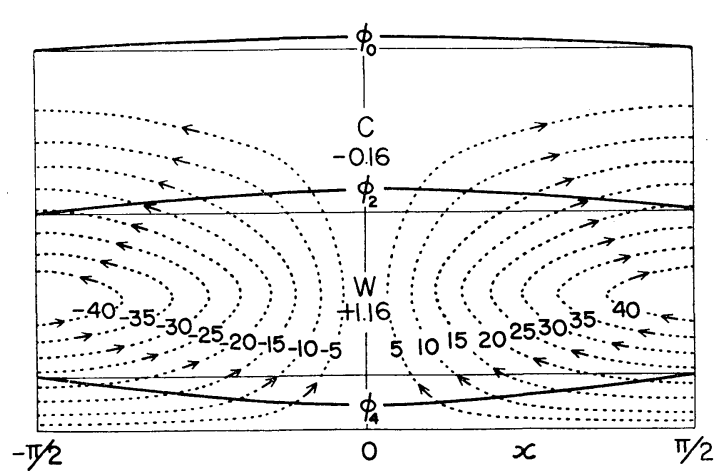

(a)

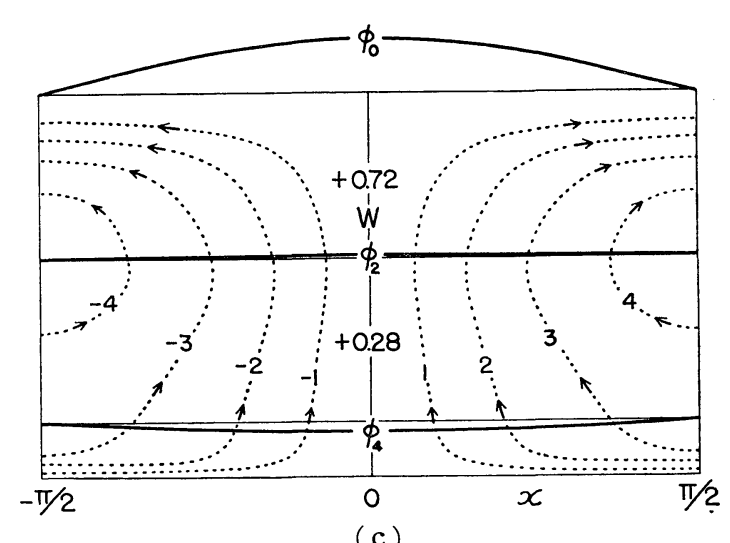

(c)

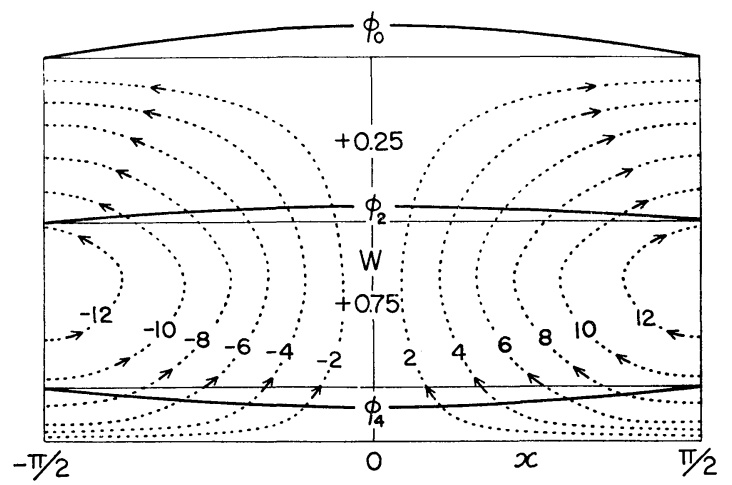

(b)

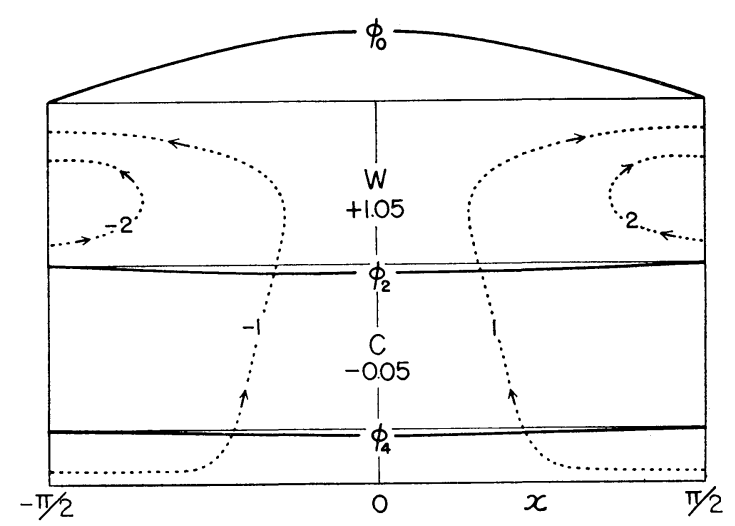

(d)

Fig. 7. Structure of developing typhoon-scale disturbances. The solid lines represent the perturbation geopotential of isobaric surfaces $\left(\phi_{0}, \phi_{2}\right.$ and $\left.\phi_{4}\right)$ and the dotted lines are streamlines. The two numbers on the central vertical axis show amplitudes of the perturbation potential temperature at the upper level and at the lower level.
(a) for $\xi=2.0$ and $\eta=0.4$
(b) for $\xi=1.5$ and $\eta=0.8$
(c) for $\xi=1.2$ and $\eta=1.1$
(d) for $\xi=1.1$ and $\eta=1.3$

Only half a wavelength is illustrated for each case.

lower layer are almost equal, nevertheless the warming in the upper layer is almost twice or three times larger than that in the lower layer. This is because the temperature change is determined as the difference between the warming due to the released heat of comdensation and the adiabatic cooling due to the ascending motion. Fig. $7 \mathrm{~d}$ corresponds to $l=0.42$. In this case in the lower layer it is cooler in the ascending region. Comparison of these figures shows that the more the partition rate of heat released in the lower layer, the larger the lowering of the geopotential of the isobaric surface at level 4 , and the stronger the circulation in the $x-p$ plane. It should be remembered that the growth rate of a typhoon-scale disturbance becomes larger as $l$ increases.
In Fig. 8 the ratio $H \equiv \theta_{a 1} / \theta_{a 3}$ is shown. In domain (a) and in domain (d) $H$ is negative. For domain (a) disturbances similar to that shown in Fig. 7a develop. For domain (d) disturbances similar to that shown in Fig. 7d develop. In domain (b), $0<H<1$ and in domain (c), $H>1$. For positive values of the quantity $H, H$ means the ratio of the warming in the upper layer to that in the lower layer. For domain (b) we obtain a disturbance such that the warming in the lower layer is larger than that in the upper layer (Fig. 7b). On the other hand for domain (c) the warming in the upper layer is larger (Fig. 7c). According to Yanai (1961a), Colón et al. (1961) and other authors, the warming in the upper layer is larger than that in the lower layer of 


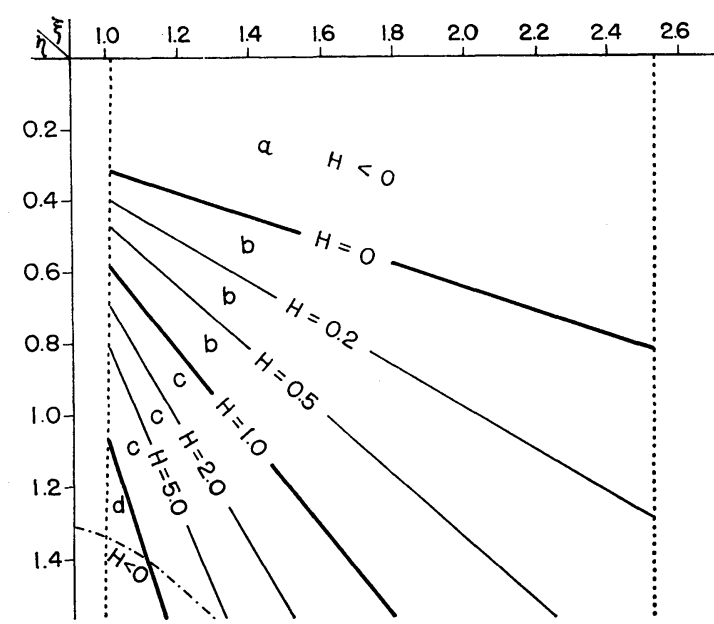

Fig. 8. The ratio $H \equiv \theta_{a 1} / \theta_{a 3}$ for a developing typhoon-scale disturbance in domain $B$ as a function of $\xi$ and $\eta$. In domain (a) and domain (d) the perturbation potential temperature in the upper layer and that in the lower layer are out of phase. In domain (b) and domain (c) the perturbation potential temperature in the upper layer is in phase with that in the lower layer.

the troposphere in tropical cyclones. In order to obtain a typhoon-scale disturbance whose thermal structure is similar to that of actual tropical cyclones, $\xi$ and $\eta$ (or $q$ and $l$ ) must be chosen in the range of domain (c) in Fig. 8. Thus $l$ should be between about 0.4 and 0.5 .

\section{Stability of perturbations in the balanced model}

In the unbalanced model we have found several different types of solutions which were not found in the balanced model by Ooyama (1963) and others. Mentioning only interesting solutions among them, one is an amplifying oscillatory wave existing in domain II. Another is an amplifying stationary wave in domain III. In order to clarify the relation between the present results and those of the balanced model, we shall discuss the same problem with the use of balanced assumptions. As balanced models we shall consider the following two models. In Case 1 we do not assume the geostrophic balance in the free atmosphere. Balance requirement is applied only to the friction layer. In Case 2, on the other hand, we assume the geostrophic balance. Concerning the method of incorporating the effect of the surface friction, in both cases we shall adopt the same assumption used by Ooyama (1963) and others, that is, we shall deal with motions in the free atmosphere by imposing the boundary condition (5.1) at level 4 .

$$
\omega_{4}=-C \frac{\partial v_{4}}{\partial x}
$$

The balanced model which has often been used by many authors corresponds to Case 2 .

The relation (5.1) is similar to that obtained from Ekman's theory on wind profile in the friction layer (Syōno; 1944, 1950). Here we shall derive (5.1) from our set of equations by requiring the balance among the frictional force, the Coriolis force and the pressure gradient force in the friction layer. Omitting time derivatives (and viscous terms) in the equations of motion at level 5, (2.19b) and (2.19d), we obtain

$$
\left.\begin{array}{c}
-f v_{5}=-\frac{\partial \phi_{4}}{\partial x}-D u_{5} \\
f u_{5}=-D v_{5}
\end{array}\right\}
$$

In determining $\omega_{4}$ from continuity relation we shall omit the contribution of $u_{4}$.

$$
\omega_{4}=\frac{\partial u_{5}}{\partial x} \frac{d \Delta p}{2}
$$

Introducing (5.2) into (5.3) we have

$$
\omega_{4}=-\frac{d \Delta p}{2} \frac{D}{D^{2}+f^{2}} \frac{\partial^{2} \phi_{4}}{\partial x^{2}}
$$

By the use of the geostrophic wind relation (5.4) leads to

$$
\omega_{4}=-C \frac{\partial v_{4}}{\partial x}
$$

where

$$
C=\frac{d \Delta p}{2} \frac{D f}{D^{2}+f^{2}}
$$

This is the same as (5.1).

If we take the values of $D, f, d$ and $\Delta p$ as used before, (5.6) gives $C=10 \mathrm{mb}$.

5.1. derivation of the frequency equation

A set of equations for the balanced model is obtained by replacing (5.1) instead of (2.19b), $(2.19 \mathrm{~d})$ and $(2.19 \mathrm{~h})$ in the set of equations (2.19). Moreover, for case $2 \partial u_{i} / \partial t$ and $\nu\left(\partial^{2} u_{i} /\right.$ 
$\left.\partial x^{2}\right)$ in (2.19a) are omitted.

The homogeneous equations for $U_{0}, U_{2}, U_{4}$ and $V_{4}$ are obtained as follows:

$$
\left(\begin{array}{cccc}
-2 r & 2 r+2 M_{1} & M_{1} & 2 b M_{1}(\eta-1) \\
0 & -2 r & 2 r+M_{3} & 2 b M_{3}(\xi-1) \\
0 & 0 & f & X \\
1 & 2 & 1 & -2 b
\end{array}\right)\left(\begin{array}{c}
U_{0} \\
U_{2} \\
U_{4} \\
V_{4}
\end{array}\right)=0
$$

where

$$
r=N X^{2}+f^{2} \text { and } b=C / \Delta p
$$

$N$ is a tracer which is set by 0 for Case 2 .

The frequency equatian for Case 1 is

$$
P X^{5}+Q X^{4}+R X^{3}+S X^{2}+T X+U=0
$$

and for case 2

$$
T X+U=0
$$

where

$$
\left\{\begin{aligned}
& P=8 \\
& Q= 4 b f \\
& R= 16 f^{2}+3\left(M_{1}+M_{3}\right) \\
& S= 8 b f^{3}-2 b f M_{1}(\eta-1)-6 b f M_{3}(\xi-1) \\
& T= 8 f^{4}+3 f^{2}\left(M_{1}+M_{3}\right)+M_{1} M_{3} \\
& U= 4 b f^{5}-2 b f^{3} M_{1}(\eta-1)-6 b f^{3} M_{3}(\xi-1) \\
&-2 b f M_{1} M_{3}(\xi-1)
\end{aligned}\right.
$$

\section{2. solution of the frequency equation}

For Case 1 one of five solutions represents a stationary wave and the others two sets of propagating waves which are amplified or damped. The phase velocities of the propagating waves are $28.6 \mathrm{~m} / \mathrm{sec}$ and $48.0 \mathrm{~m} / \mathrm{sec}$, and they depends little on values of $\xi$ and $\eta$. The growth rates of the amplifying propagating waves are comparable to those of propagating waves which are amplified by including the surface friction in our unbalanced model. For Case 2, as is seen from (5.7), only a stationary wave is found and propagating waves are completely eliminated. Numerical calculation shows that the growth rate of a stationary wave for Case 1 is approximately given by a solution for Case 2. The condition for having an amplifying stationary wave in the balanced model is shown in a diagram with $\xi$ as abscissa and $\eta$ as ordinate (Fig. 9).

For $k^{2} \gg f^{2} /(\Delta p)^{2} B S$, namely for the wave-

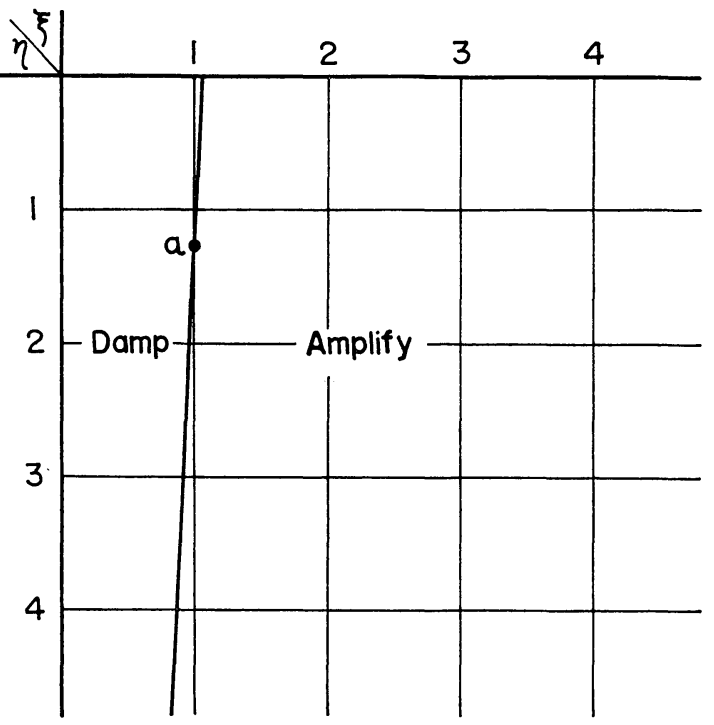

Fig. 9. Two domains in $\xi-\eta$ space dividing the property of a stationary wave.in the balanced model (for $\nu=0$ ).

length $L \ll 4,000 \mathrm{~km}$ if $f, \Delta p, B$ and $S$ are taken equal to values used before, an approximate solution corresponding to the stationary wave is given by

$$
X \doteqdot 2 b f(\xi-1)
$$

where $b$ is a measure of the effect of the surface friction and may be taken equal to 0.03 . For example, when we take $\xi=2.0$, the growth rate of this wave is $3 \times 10^{-6} \mathrm{sec}^{-1}$ for $\nu=0$.

5.3. discussion

For both of Case 1 and Case 2 we found an amplifying stationary wave whose growth rate is approximately given by (5.8) for the wavelength $L \ll 4,000 \mathrm{~km}$, and it is comparable to that of tropical cyclones. The property of this wave is almost identical to that found by Ooyama (1963) and other authors and is similar to the stationary wave which was obtained in domain $B$ in our unbalanced model. Comparing Fig. 9 with Fig. 4, we see that the condition for having such a wave is different between the balanced model and the unbalanced model. For the balanced model the condition is approximately $\xi \geq 1.0$. On the other hand for the unbalanced model $1.0 \leq \xi \leq 2.5$ must be satisfied. This point will be discussed later again.

Another difference concerning this type of disturbances between the balanced and the 


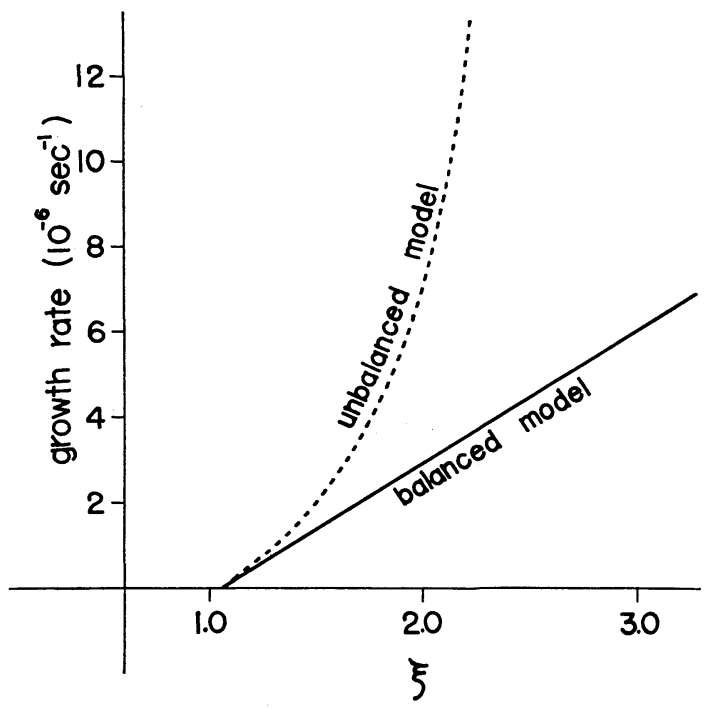

Fig. 10. Comparison of the growth rate of developing typhoon-scale disturbance in the balanced model with that in the unbalanced model. The curves are drawn for $\eta=0, \nu=0$ and the wavelength of the disturbance $L=400 \mathrm{~km}$.

unbalanced models is found in the dependency of the growth rate on $\xi$. Fig. 10 shows the growth rate of this disturbance as a function of $\xi$ (for $\eta=0$ as an example). The solid line represents the growth rate for the balanced model and the dotted line for the unbalanced model. The growth rate of the typhoon-scale disturbance is larger in the unbalanced model than that in the balanced model. The difference becomes larger as the value of $\xi$ is increased. This is interpreted as follows. In a model in which (5.1) is assumed, only the frictional effect causes the horizontal convergence in the surface boundary layer. On the other hand in the unbalanced model in which (5.1) is not assumed, the allobaric effect as well as the frictional effect cause the horizontal convergence. As $\xi$ is increased from about 1.0 to 2.5 , the allobaric effect becomes relatively larger compared with the frictional effect. Thus the difference between the growth rate of the typhoon-scale disturbance in the unbalanced model and that in the balanced model becomes larger due to the increased allobaric effect as $\xi$ is increased. (Even in a case when the frictional convergence is very small compared with the horizontal convergence due to the allobaric effect, provided $\xi \leq 2.5$, the existence of surface friction is es- sential to developing typhoon-scale disturbances, as was mentioned in section 3.)

In the unbalanced model when $\xi$ exceeds a critical value (about 2.5 in our model), the horizontal convergence is caused only by the allobaric effect. The surface friction acts rather to suppress the convergence. In this case an amplifying wave becomes a gravity wave of small scale. In a model in which (5.1) is assumed, the allobaric effect is not taken into account. Therefore, for all values of $\xi \gtrless 1.0$, the frictional effect causes the horizontal convergence and typhoon-scale disturbances develop. These seem to suggest that for $\xi \geq 2.5$ the assumption (5.1) should not be permitted.

In the balanced model amplifying oscillatory waves in domain II as well as amplifying stationary wave in domain III are eliminated. This elimination is closely related to the assumption (5.1). In adiabatic case there exist two types of propagating waves whose phase velocities are different each other. For the unbalanced model they are modified by heating into amplifying propagating waves in domain II and into amplifying stationary waves in domain III. On the other hand for the model in which (5.1) is assumed, such modifications are not made and the phase velocity of the gravity waves depends little on $\xi$ and $\eta$, unlike the case of the unbalanced model.

By assuming the geostrophic balance in the free atmosphere in addition to the assumption (5.1) in the friction layer any gravity oscillations are eliminated. However, for eliminating undesirable gravity waves such as amplifying oscillatory waves, only the assumption (5.1) is sufficient and the geostrophic balance in the free atmosphere is not necessary.

\section{Comparison of the unconditional heating case with the conditional heating case}

We have assumed that (2.21) holds regardless of the sign of $\omega_{4}$ in the perturbation analysis. When the horizontal divergence occurs in the friction layer, it is more realistic that we set $Q=0$ in the air column above. Our interest is to know how results already obtained for the unconditional heating case are modified for such conditional heating case. In this section this problem will be investigated by numerical time integrations of the linearized 
system (2.19). We shall confine discussions to the unbalanced model mentioned in section 3 .

We shall consider a disturbance which is cyclic in the $x$-direction. The wavelength is taken equal to $200 \mathrm{~km}$. The initial disturbance is given by

$$
\left\{\begin{array}{l}
v=5 \sin 2 \pi x / L \\
u=0 \\
\omega=0
\end{array} \quad \text { at } t=0\right.
$$

where $L=200 \mathrm{~km}$ and $v$ is independent of height at initial time and the unit is $\mathrm{m} / \mathrm{sec}$. The potential temperature $\theta$ and the geopotential $\phi$ are determined so as to satisfy the hydrostatic and the geostrophic balances. The horizontal mesh size $\Delta x$ is taken equal to 10 $\mathrm{km}$. The waves which have maximum growth rate among waves which such mesh size can express will be pronounced as time goes on. The time increment $\Delta t$ is chosen as 60 seconds.

(1) Case I ( $\xi=1.8, \eta=0.8)$

The values of $\xi$ and $\eta$ used in this case correspond to a point in domain IB of the $\xi-\eta$ diagram, and correspond to $q=20.5 \mathrm{~g} / \mathrm{kg}$ and $l=0.67$, namely $67 \%$ of the total amount of the released latent heat is given to the lower layer and $33 \%$ is given to the upper layer. From the perturbation analysis for the unconditional heating case it is expected that the disturbance with several hundred kilometers of the horizontal scale develops gradually and besides gravity oscillatory waves should also be amplified slowly. We assume $\nu=10^{3} \mathrm{~m}^{2} \mathrm{sec}^{-1}$ for this case. Fig. 11a shows the time change of $\theta_{3}$ at some point. Fig. 11b shows the horizontal profiles of $\omega_{3}$. The solid line is drawn for the unconditional heating case and the dotted line for the conditional heating case.

It is seen from Fig. 11a that for the unconditional heating case oscillatory waves superimposed on the developing disturbances are amplified as expected from the perturbation analysis. However, it should be emphasized that for the conditional heating case such amplifying oscillations are eliminated or becomes invisible. Thus, for the conditional heating case we can obtain the disturbance whose growth rate and the horizontal scale are similar to those of tropical cyclones without any trouble, if we choose the values of $\xi$ and $\eta$ (or $q$ and $l$ ) corresponding to domain IB.

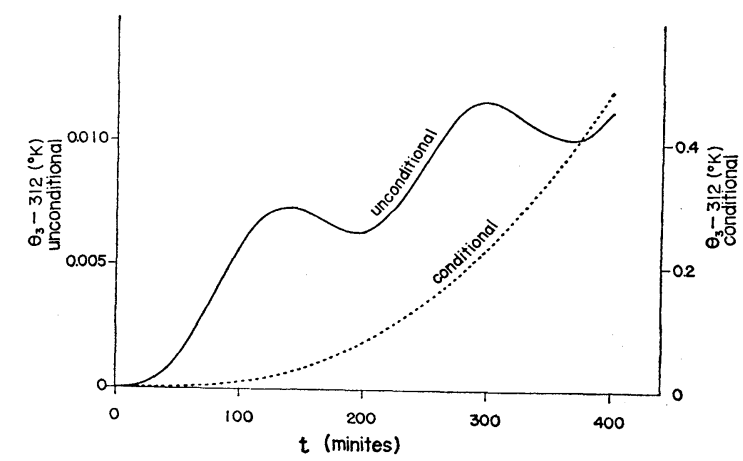

Fig. 11a. Time variation of $\theta_{3}$ in case $I$ for the unconditional heating and that for the conditional heating at $x=15 \mathrm{~km}$.

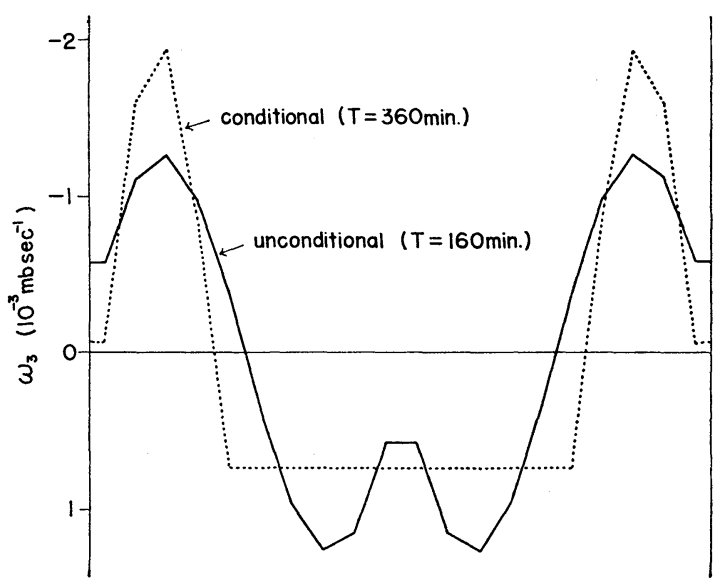

Fig. 11b. Horizontal profiles of $\omega_{3}$ at 160 minutes from the initial time for the unconditional heating and $\omega_{3}$ at 360 minutes for the conditional heating in Case I.

(2) Case II $(\xi=0.0, \eta=2.0)$

As an example when small scale gravity oscillatory waves are amplified with the very large amplification rate, we chose $\xi=0.0$ and $\eta=2.0$, which corresponds to $q=17 \mathrm{~g} / \mathrm{kg}$ and $l=0$, namely all the amount of released heat is given to the upper layer. The value of $\nu$ is taken equal to $10^{4} \mathrm{~m}^{2} \mathrm{sec}^{-1}$. The time change of $\omega_{1}, \omega_{3}$ and $\theta_{1}$ (their points are in the same vertical column of air) is shown for the unconditional heating case in Fig. 12a. It is seen that oscillations with about 15 minutes of period are amplified rapidly. The horizontal preferred scale of this oscillatory wave is the minimum wavelength which grid size used here can express, as expected from Fig. 3 (the curve for propagating wave).

The relation among the phases of $\omega_{1}, \omega_{3}$ and 


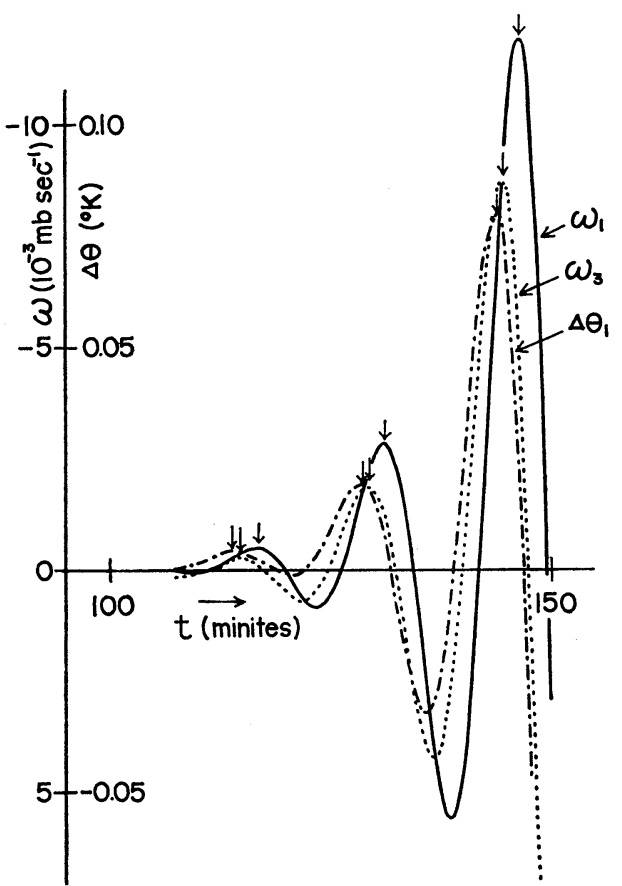

Fig. 12a. Time variations of $\omega_{1}, \omega_{3}$ and $\theta_{1}$ at $x=$ $15 \mathrm{~km}$ in case II for the conditional heating. The arrows show the time when they take extreme values.

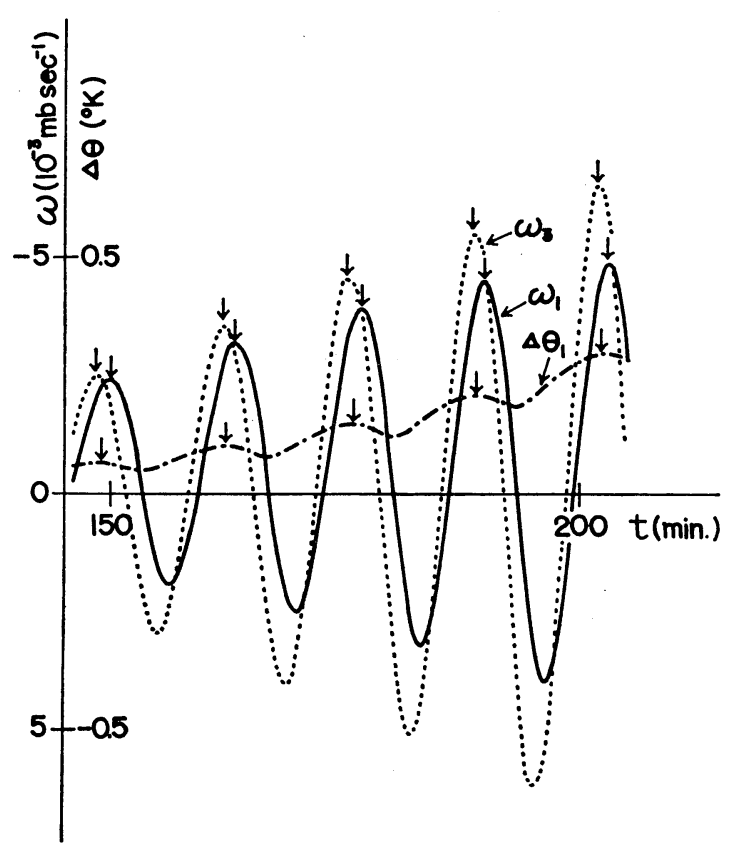

Fig. 12b. Same as Fig. 12a except for the conditional heating.

$\theta_{1}$ should be noted. In a neutral oscillation $-\omega_{1}$ has the phase lag of a quarter of the period of oscillation to $\theta_{1}$. In case II the phase lag is about 2 minutes, namely, $1 / 7 \sim 1 / 8$ of the period. This shows the conversion from the potential energy to the kinetic energy of waves by the negative correlation between $\theta_{1}$ and $\omega_{1}$. The correlation between $\omega_{3}$ and $\theta_{3}$ is nearly zero in general in the amplifying oscillatory waves in domain II. The phase lag of $-\omega_{1}$ to $-\omega_{3}$ is 1 or 2 minutes. That is, the vertical axis of the circulation in the $x$ - $p$ plane is slightly tilted upward against the direction of the propagation of this wave.

The time change of $\omega_{1}, \omega_{3}$ and $\theta_{1}$ for the conditional heating case is shown in Fig. 12b. Concerning the amplification of gravity oscillations, the result is almost the same as the unconditional heating case, but the amplification rate becomes smaller.

(3) Case III $(\xi=3.0, \eta=0.0)$

In this case small scale stationary waves are expected to grow very rapidly. The values $\xi=3.0$ and $\eta=0.0$ corresponds to $q=23 \mathrm{~g} / \mathrm{kg}$ and $l=1.0$, namely all the amount of the released heat is given to the lower layer. We take $\nu=10^{4} \mathrm{~m}^{2} \mathrm{sec}^{-1}$. Fig. 13a shows the time change of $\omega_{3}$ at some point and Fig. 13b shows the horizontal profile of $\omega_{3}$. The solid line represents the unconditional heating case and the dotted line shows the conditional heating case.

For the unconditional heating case small

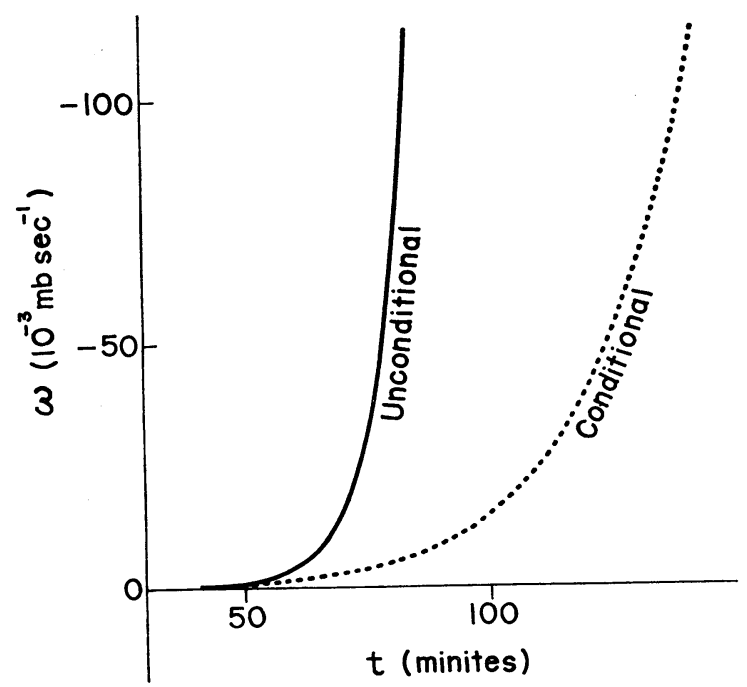

Fig. 13a. Time variation of $\omega_{3}$ in case III. The solid line shows the variation $\omega_{3}$ at $x=15 \mathrm{~km}$ for the unconditional heating and the dotted line for $\left(\omega_{3}\right.$ at $x=25 \mathrm{~km}$ for the conditional heating. 


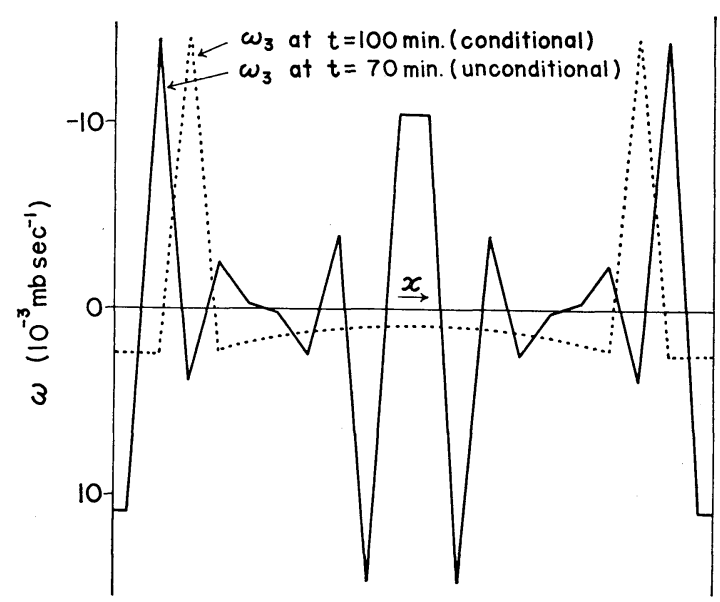

Fig. 13b. Horizontal profiles of $\omega_{3}$ in case III. The solid line represents the profile at 70 minutes from the initial time for the unconditional heating and the dotted line the profiles at 100 minutes for the conditional heating.

scale disturbances grow very rapidly. For the conditional heating case the weak descending motion occurs over a wide region and the strong ascending motion is concentrated in a narrow region, as discussed by Haque (1952). Also in this case the growth rate is smaller in the conditional heating case than in the unconditional heating case.

\section{Application to axially symmetrical dis- turbances}

We have discussed the stability of slab symmetrical disturbances instead of axially symmetrical ones for the sake of simplicity. In this section we shall show that results obtained for slab symmetrical disturbances are qualitatively true for axially symmetrical ones. For this purpose some numerical time integrations of a set of linearized equations are carried out for axially symmetrical case and only for the conditional heating case.

The numerical calculations are performed for three cases corresponding to those for slab symmetrical cases mentioned in the previous section, but for the Cases II and III, results are almost the same as before. We shall show only results of the case when a typhoon-scale axially symmetrical disturbance develops.

The inner and the outer boundary conditions are as follows:

$$
v_{r}=v_{\theta}=\frac{\partial \theta}{\partial r}=0 \text { at } r=0 \text { and } r=r_{0}
$$

where $v_{r}$ is the radial velocity, $v_{\theta}$ the trangential velocity, $r$ the radius and $r_{0}$ is taken equal to $2,410 \mathrm{~km}$. The initial conditions for $v_{r}$ and $\omega$ are $v_{r}=\omega=0$ everywhere and $v_{\theta}$ is

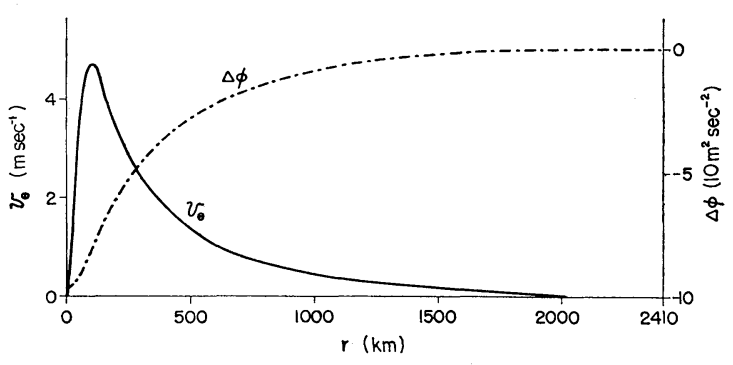

Fig. 14a. Intitial profiles of $v_{\theta 4}$ and $\phi$ for axially symmetrical case.

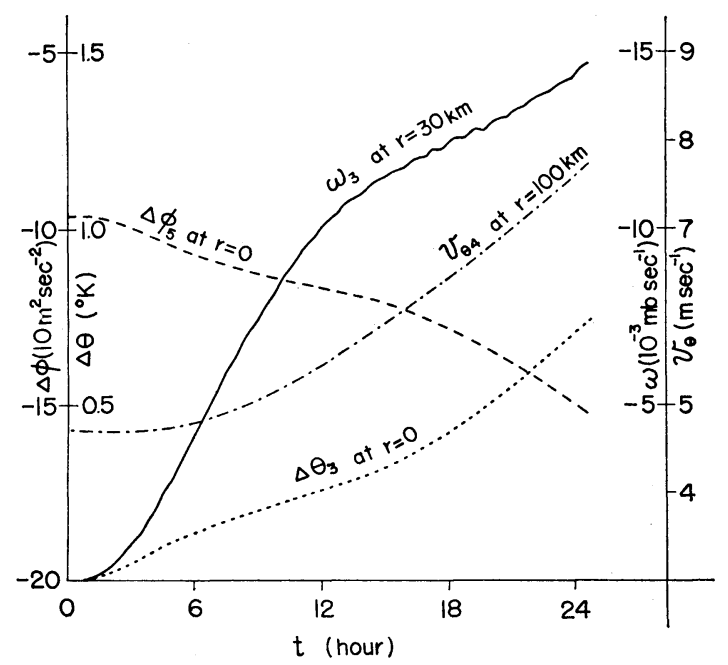

Fig. 14b. Time variations of $\phi_{5}$ and $\theta_{3}$ at the center, $\omega_{3}$ at $r=30 \mathrm{~km}$, and $v_{\theta 4}$ at $r=100 \mathrm{~km}$ for axially symmetrical case.

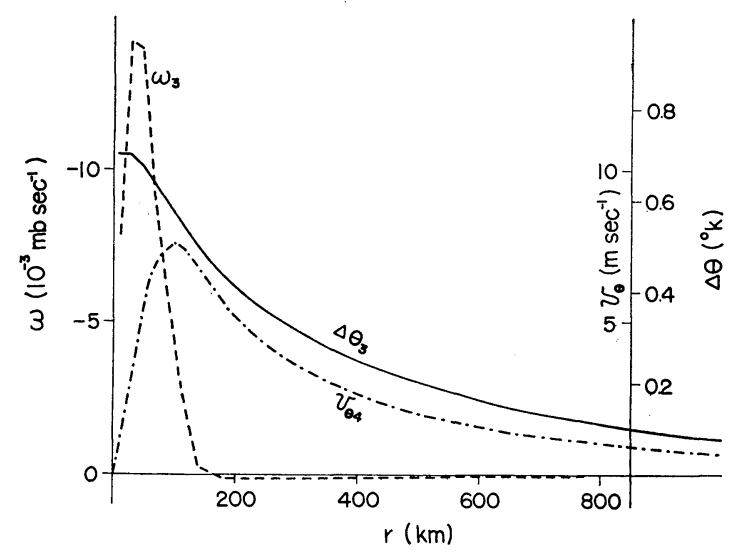

Fig. 14c. Horizontal profiles of $\omega_{3}, \theta_{3}$ and $v_{\theta 4}$ at 24 hours from the initial time for axially symmetrical case. 
independent of the height. The horizontal profile of $v_{\theta}$ is shown in Fig. 14a. The potential temperature $\theta$ and the geopotential $\phi$ are determined to satisfy the hydrostatic and the geostrophic relations. The horizontal profile of $\phi$ at the initial time is also shown in Fig. 14a.

Fig. 14b shows the time change of the geopotential at level 5 and the potential temperature in the lower layer at the center. For the first 24 hours the drop of the corresponding surface pressure is about $0.5 \mathrm{mb}$ and the potential temperature in the lower layer is increased in about $0.7^{\circ} \mathrm{K}$. Fig. $14 \mathrm{~b}$ also shows the time change of the vertical $p$-velocity at level 3 at $r=30 \mathrm{~km}$ and the tangential velocity at level 4 at $r=100 \mathrm{~km}$. The horizontal profiles of $\omega_{3}$, $v_{\theta 4}$ and $\theta_{3}$ are shown in Fig. 14c. From these figures we see that a typhoon-scale disturbance is developing gradually.

For the slab symmetrical case the horizontal difference of the potential temperature is only $0.002^{\circ} \mathrm{K}$ for the first 400 minutes, while for this case it attains $0.15^{\circ} \mathrm{K}$. In the axially symmetrical disturbance, a strong ascending motion is concentrated in the central region and a weak descending motion spreads over wide outer region. Thus the adiabatic heating in the outer region by the descending motion becomes small and the horizontal temperature difference becomes large.

\section{Concluding remarks}

We have discussed some properties of motions which are driven by latent heat released by cumulus clouds embedded in a conditionally unstable atmosphere with the use of a set of unfiltered equations. It was assumed that the total amount of heat released in a vertical column of air is proportional to the horizontal convergence in the surface boundary layer. Under such an assumption if $q$ (the mixing ratio of water vapor to air ascending through the top of the surface layer) and $l$ (the ratio of the amount of heat released in the lower layer to the total amount of heat released in a vertical column of air) are within some range (domain IB as shown in Fig. 6), a typhoonscale disturbance develops. This disturbance is similar to that obtained by Ooyama (1963), Charney and Eliassen (1964) and Ogura (1964) with the use of the balanced model. The growth rate of the typhoon-scale disturbance becomes larger when either $\xi$ and $\eta$ is increased and static stability of the atmosphere is decreased. For a disturbance in which the warming in the upper layer is larger than that in the lower layer, as observed in actual tropical cyclones, the vertical partition rate of heat $l$ takes a value between about 0.4 and about 0.5 .

Ooyama and other authors assumed the geostrophic (or gradient wind) balance in the free atmosphere in discussing tropical cyclone development. They treated the surface boundary layer separately and assumed that in this layer the frictional force is balanced with the pressure gradient force and the Coriolis force. In the present work we obtained the typhoonscale disturbance as one of several types of motions without the two assumptions mentioned above. The assumption of the balance in the surface layer filters out two types of unstable gravity waves found for the unbalanced model. One of them is a stationary unstable gravity wave in domain III which is similar to that obtained by Haque (1952), Syōno (1953) and others, and another is an amplifying propagating wave in domain II. The assumption of the balance in the free atmosphere filters out neutral gravity oscillations. In the balanced model used by Ooyama and others the assumption of the balance in the surface layer seems to be essential for eliminating undesirable disturbances.

Although a model in which the balance in the surface layer is assumed has an advantage of filtering such unstable gravity waves, it modifies the condition for having a typhoonscale disturbance and its growth rate. In such a balanced model the horizontal convergence in the surface layer is caused only by the surface friction, while in the unbalanced model the convergence is caused by the allobaric effect as well as the surface friction and therefore the growth rate of a typhoon-scale disturbance is larger than that in the balanced model. The comparison was shown in Fig. 10. When the amount of heat released in the lower layer exceeds a critical value (in domain III in Fig. 2 or 6), in the unbalanced model unstable gravity waves grow very rapidly instead of a typhoonscale disturbance. On the other hand in the balanced model even under such a condition a typhoon-scale disturbance still develops. 
An amplifying propagating wave in domain II found in the unbalanced model has a very large amplification rate as well as an amplifying stationary wave in domain III has (Fig. 6 and Fig. 3). The amplifying propagating wave is found when the relatively large part of the released heat is given to the upper layer. We do not know whether or not such a wave exists in the real atmosphere. When we parameterize the effect of cumulus convection on large scale motions in different manners, such amplifying gravity oscillations may not be found.

When the effect of the surface friction is not taken into account, we do not find a typhoon-scale disturbance in the present model. It seems that the growth rate and the horizontal scale of a developing disturbance are similar to those of tropical cyclones only when the horizontal convergence in the surface layer is caused by the effect of the surface friction.

From the perturbation analysis for the unbalanced model and some numerical time integrations of a set of linearized equations shown in sections 6 and 7 , it was found that under the condition corresponding to domain IB in Fig. 6 we can obtain a typhoon-scale disturbance by numerical time integrations even if we use primitive equations. Moreover, under the condition corresponding to domain (c) in Fig. 8 we shall obtain a disturbance whose thermal structure is similar to that of an actual tropical cyclone.

Here we shall note the following point. Although from the perturbation analysis we have derived the condition concerning the vertical partition of released heat so that we may succeed in a numerical simulation of tropical cyclone development, we do not know what the vertical distribution of heat sources is in the real atmosphere. How does cumulus convection distribute heat vertically? By what is the vertical partition of the released heat determined? These may be very important problems in the future.

Based upon the results of this study, numerical time integrations to simulate tropical cyclone development have been made successfully with the use of non-linear primitive equations. These will be reported elsewhere (Yamasaki, 1967).

\section{Acknowledgments}

The authors wish to express their thanks to Drs. K. Miyakoda, T. Matsuno and M. Yanai for their helpful discussions and suggestions. Thanks are also due to Dr. K. Mohri of the Japan Meteorological Agency who provided the authors with the convenience to use the computing machine, IBM 704. This reseach has been partially supported through a grant from the Japan Society for the promotion of Science as part of the Japan-U.S. Cooperative Science Program. Thanks are extended to Mrs. I. Akamatsu for drawing the figures and to Miss M. Onozuka for typing the manuscript.

\section{References}

Charney, J. G., and A. Eliassen, 1964: On the growth of the hurricane depression. J. atmos. Sci.,21, 68-75.

Colón, J.A. and staff, 1961: On the structure of hurricane Daisy (1958). National Hurircane Reseach Project, U.S. Weather Bureau, Report No. $48,102 \mathrm{pp}$.

Haque, S.M.A., 1952: The initiation of cyclonic circulation in a vertically unstable stagnant air mass. Quart. J. Roy. meteor. Soc., 78, 394-406.

Kasahara, A., 1961: A numerical experiment on the development of a tropical cyclone. J. meteor., 18, 259-282.

Kuo, H.L., 1961 : Convection in conditionally unstable atmosphere. Tellus, 13, 441-459.

-1965 : On formation and intensification of tropical cyclones through latent heat release by cumulus convection. J. atmos. Sci., 22, 4063.

Lilly, D.K., 1960 : On the theory of disturbances in a conditionally unstable atmosphere. Mon. Wea. Rev., 88, 1-17.

Malkus, J.S. and H. Riehl, 1960: On the dynamics and energy transformations in steady state hurricanes. Tellus, 12, 1-20.

Ogura, Y., 1964: Frictionally controlled, thermally driven circulations in a circular vortex with application to tropical cyclones. J. atmos. Sci., 21, 610-621.

Ooyama, K., 1963 : A dynamical model for the study of tropical cyclone development. Department of Meteorology and Oceanography, New York University, $26 \mathrm{pp}$.

Riehl, H. and J.S. Malkus, 1961: Some aspects of hurricane Daisy, 1958. Tellus, 13, 181-213.

Syono, S., 1944: Approximate solution of non-linear differential equations of stationary winds in 
axial symmetric cyclone and anticyclone and its application. J. meteor. Soc. Japan, 22, 365391 (in Japanese).

, 1950: On the vortical rain. Geophys. Notes, Tokyo Univ., 3, 25-27.

, 1953 : On the formation of tropical cyclones. Tellus, 5, 179-195.

- 1962: A numerical experiment of the formation of tropical cyclones. Proc. Internat. Symposium on Numerical Weather Prediction,
1960. Meteor. Soc. Japan, Tokyo, 405-418.

Yamasaki, M., 1967: Numerical simulation of tropical cyclone development with the use of primitive equations. To be published in this Journal. Yanai, M., 1961a: A detailed analysis of typhoon formation. J. meteor. Soc. Japan, 39, 187-213. , 1961b: Dynamical aspects of typhoon formation. J. meteor. Soc. Japan, 39, 282-309.

,- 1964 : Formation of tropical cyclones. Rev. Geophys., 2, 367-414.

\title{
地表摩擦の存在下で積雲対流による潜熱の放出によって ひき起される運動の安定性
}

\author{
正野 重方, 山岬 正紀 \\ 東京大学理学部地球物理学教室
}

台風の発澾を数値的飞実現するための理論的基礎を得るために，積雲対流により放出される潜熱とよってひき起さ れる運動の性質を, 摩擦層掞よび自由大気二層から成る三層モデル飞適用した摄動方程式を解いて調べた。自由大気, 摩擦層ともに，水平方向の運動方程式としては，プリミティブ方程式を用いた。放出される熱量は摩擦層での空気の 収歛量に比例すると仮定した。

大山 (1963), Charney and Eliassen (1964), 小倉 (1964) そよって, バランスモデルに対して見出された台風 スケールの擾乱はプリミティブモデルであ見出された。ただし，プリミティブモデルでは，収歛空気の含む氷蒸気量

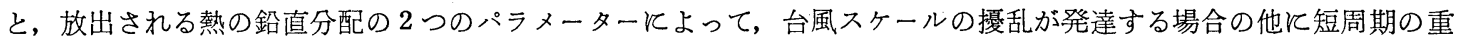
力振動が増幅する場合, 小規模擾乱が急速飞発達する場合とがある。地表摩擦を考虑に入れなければ，台風スケール の擾乱は見出されない。一方後二者は地表摩擦の存在にほとんど影響されない不安定重力波である。

大山等の結果との関係を明らかとするためと，2つの種類のバランスモデルとついても論じてみた結果，大山等の モデルでこれら 2 つ不安定重力波をとり除いていたものは, 摩擦層飞扣けるバランス（摩擦力, コリオリカ, 気圧 傾度力の間）の仮定であること, この仮定を用いた場合には, 自由大気中での地衡風（又は傾度風）のバランスの仮 定は，ほほ中立な重力振動をとり除く意味しかもっていないこと等がわかった。双摩擦層でのバランスの仮定は，上 にのベた不安定重力波を除くけれどあそれは同時に台風スケールの擾乱の成長率やその存在条件を変える。

損乱の性質をきめる要素としては, 収歛空気の混合比扣よび大気の安定度の他に, 熱の鉛直分配も重要な要素であ ることがわかった。 